\title{
Estimating regional methane surface fluxes: the relative importance of surface and GOSAT mole fraction measurements
}

\author{
A. Fraser ${ }^{1}$, P. I. Palmer ${ }^{1}$, L. Feng ${ }^{1}$, H. Boesch ${ }^{2}$, A. Cogan $^{2}$, R. Parker ${ }^{2}$, E. J. Dlugokencky ${ }^{3}$, P. J. Fraser ${ }^{4}$, \\ P. B. Krummel ${ }^{4}$, R. L. Langenfelds ${ }^{4}$, S. O'Doherty ${ }^{5}$, R. G. Prinn ${ }^{6}$, L. P. Steele ${ }^{4}$, M. van der Schoot ${ }^{4}$, and R. F. Weiss ${ }^{7}$ \\ ${ }^{1}$ School of GeoSciences, University of Edinburgh, Edinburgh, UK \\ ${ }^{2}$ Earth Observation Science Group, Space Research Centre, University of Leicester, Leicester, UK \\ ${ }^{3}$ US National Oceanic and Atmospheric Administration, Global Monitoring Division, Earth System Research Laboratory, \\ Boulder, Colorado, USA \\ ${ }^{4}$ Centre for Australian Weather and Climate Research, CSIRO Marine and Atmospheric Research, Aspendale, Victoria, \\ Australia \\ ${ }^{5}$ School of Chemistry, University of Bristol, Bristol, UK \\ ${ }^{6}$ Center for Global Change Science, Department of Earth, Atmospheric, and Planetary Science, Massachusetts Institute of \\ Technology, Cambridge, Massachusetts, USA \\ ${ }^{7}$ Scripps Institution of Oceanography, UCSD, La Jolla, California, USA
}

Correspondence to: A. Fraser (ac.fraser@ed.ac.uk)

Received: 12 November 2012 - Published in Atmos. Chem. Phys. Discuss.: 3 December 2012 Revised: 8 April 2013 - Accepted: 13 May 2013 - Published: 13 June 2013

\begin{abstract}
We use an ensemble Kalman filter (EnKF), together with the GEOS-Chem chemistry transport model, to estimate regional monthly methane $\left(\mathrm{CH}_{4}\right)$ fluxes for the period June 2009-December 2010 using proxy dry-air columnaveraged mole fractions of methane $\left(\mathrm{XCH}_{4}\right)$ from GOSAT (Greenhouse gases Observing SATellite) and/or NOAA ESRL (Earth System Research Laboratory) and CSIRO GASLAB (Global Atmospheric Sampling Laboratory) $\mathrm{CH}_{4}$ surface mole fraction measurements. Global posterior estimates using GOSAT and/or surface measurements are between $510-516 \mathrm{Tg} \mathrm{yr}^{-1}$, which is less than, though within the uncertainty of, the prior global flux of $529 \pm 25 \mathrm{Tg} \mathrm{yr}^{-1}$. We find larger differences between regional prior and posterior fluxes, with the largest changes in monthly emissions $\left(75 \mathrm{Tg} \mathrm{yr}^{-1}\right)$ occurring in Temperate Eurasia. In non-boreal regions the error reductions for inversions using the GOSAT data are at least three times larger (up to $45 \%$ ) than if only surface data are assimilated, a reflection of the greater spatial coverage of GOSAT, with the two exceptions of latitudes $>60^{\circ}$ associated with a data filter and over Europe where the surface network adequately describes fluxes on our model spatial and temporal grid. We use CarbonTracker and GEOSChem $\mathrm{XCO}_{2}$ model output to investigate model error on
\end{abstract}

quantifying proxy GOSAT $\mathrm{XCH}_{4}$ (involving model $\mathrm{XCO}_{2}$ ) and inferring methane flux estimates from surface mole fraction data and show similar resulting fluxes, with differences reflecting initial differences in the proxy value. Using a series of observing system simulation experiments (OSSEs) we characterize the posterior flux error introduced by nonuniform atmospheric sampling by GOSAT. We show that clear-sky measurements can theoretically reproduce fluxes within $10 \%$ of true values, with the exception of tropical regions where, due to a large seasonal cycle in the number of measurements because of clouds and aerosols, fluxes are within $15 \%$ of true fluxes. We evaluate our posterior methane fluxes by incorporating them into GEOS-Chem and sampling the model at the location and time of surface $\mathrm{CH}_{4}$ measurements from the AGAGE (Advanced Global Atmospheric Gases Experiment) network and column $\mathrm{XCH}_{4}$ measurements from TCCON (Total Carbon Column Observing Network). The posterior fluxes modestly improve the model agreement with AGAGE and TCCON data relative to prior fluxes, with the correlation coefficients $\left(r^{2}\right)$ increasing by a mean of 0.04 (range: -0.17 to 0.23 ) and the biases decreasing by a mean of $0.4 \mathrm{ppb}$ (range: -8.9 to $8.4 \mathrm{ppb}$ ). 


\section{Introduction}

Atmospheric in situ mole fraction measurements of methane $\left(\mathrm{CH}_{4}\right)$ have been used extensively to estimate emissions of methane using "top-down" assimilation or inversion schemes (e.g. Rigby et al., 2008; Bousquet et al., 2006; Chen and Prinn, 2006; Wang et al., 2004; Houweling et al., 1999). Although the global annual methane budget is well constrained using these surface data, substantive discrepancies between estimates remain at the regional/subcontinental spatial scale and in terms of seasonal cycles (e.g. Kirschke et al., under review, 2013). Total column space-borne retrievals of methane are now available from several instruments, notably from SCIAMACHY (SCanning Imaging Absorption SpectroMeter for Atmospheric CHartographY, 2002-2012, Schneising et al., 2011; Frankenberg et al., 2011) and GOSAT (Greenhouse gases Observering SATellite, launched 2009, Kuze et al., 2009). SCIAMACHY data have been used in previous studies to estimate emissions (Spahni et al., 2011; Bergamaschi et al., 2009, and references therein).

Here, we build on previous work (Parker et al., 2011), in which we compared GOSAT retrievals of dry-air columnaveraged mole fraction of methane $\left(\mathrm{XCH}_{4}\right)$ and the corresponding GEOS-Chem model fields. In that study we found very good agreement on both annual and monthly time scales, with no significant bias, and the model capturing $>70 \%$ of the variability, with some differences over key source regions such as Southeast Asia which we attributed to known uncertainties in the bottom-up inventories. In this paper, we exploit those spatial and temporal differences using an ensemble Kalman filter to assimilate $\mathrm{XCH}_{4}$ GOSAT retrievals and surface flask $\mathrm{CH}_{4}$ measurements and infer methane fluxes.

In Sect. 2 we discuss the space-borne and ground-based measurements used in the assimilations. Section 3 describes the GEOS-Chem chemical transport model. We discuss the ensemble Kalman filter scheme in Sect. 4. Results from the assimilation are presented in Sect. 5. Conclusions are given in Sect. 6.

\section{Data}

GOSAT, launched in a sun-synchronous orbit by the Japanese Space Agency in January 2009, provides global short-wave infrared (SWIR) radiances which allow the retrieval of $\mathrm{XCO}_{2}$ and $\mathrm{XCH}_{4}$ with global coverage every three days (Kuze et al., 2009). The GOSAT scientific payload comprises the Thermal And Near infrared Sensor for carbon Observations - Fourier Transform Spectrometer (TANSO-FTS) and the Cloud and Aerosol Imager (TANSO-CAI).

Here we include a brief description of the University of Leicester proxy $\mathrm{XCH}_{4}$ retrieval algorithm, and refer the reader to Parker et al. (2011), and references therein, for further details. $\mathrm{XCH}_{4}$ is retrieved using the proxy $\mathrm{CO}_{2}$ method
(Frankenberg et al., 2011) using the OCO (Orbiting Carbon Observatory) retrieval algorithm (Boesch et al., 2006, 2011; Cogan et al., 2012), modified for use with TANSO-FTS spectra. $\mathrm{XCH}_{4}$ and $\mathrm{XCO}_{2}$ retrievals are performed sequentially at 1.65 and $1.61 \mu \mathrm{m}$, respectively. The ratio of the two species, using $\mathrm{XCO}_{2}$ as a proxy for the light path through the atmosphere, minimizes spectral artefacts due to aerosol scattering and instrument lightpath effects. To obtain a mole fraction of $\mathrm{XCH}_{4}$, we use model $\mathrm{XCO}_{2}$ from a global 3-D model:

$\mathrm{XCH}_{4}{ }^{\mathrm{PROXY}}=\left[\frac{\mathrm{XCH}_{4}}{\mathrm{XCO}_{2}}\right]^{\mathrm{GOSAT}} \times \mathrm{XCO}_{2}{ }^{\mathrm{MODEL}}$.

We have used location and time specific model output from the GEOS-Chem (Feng et al., 2011) and CarbonTracker (Peters et al., 2007) models, which are convolved with scenedependent averaging kernels from the GOSAT $\mathrm{XCO}_{2}$ retrievals and normalized so that the annual global mean is consistent with the GOSAT $\mathrm{XCO}_{2}$. From here on in, we refer to the $\mathrm{XCH}_{4}$ measurements scaled by GEOS-Chem $\mathrm{XCO}_{2}$ as the GC proxy data and those scaled by CarbonTracker $\mathrm{XCO}_{2}$ as the CT proxy data. We apply the data filtering from Parker et al. (2011), which includes cloud-screening and only uses retrievals over land. We further filter for solar zenith angle $\left(<70^{\circ}\right)$, latitude $\left(60^{\circ} \mathrm{S} \leq\right.$ lat $\left.\leq 60^{\circ} \mathrm{N}\right)$, and instrument gain (high-gain only). We apply this conservative filtering to avoid potentially spurious data resulting from retrievals made over snow and ice.

We also assimilate weekly surface $\mathrm{CH}_{4}$ data from 48 sites of the NOAA Earth System Research Laboratory (ESRL), Global Monitoring Division, version 2011-10-14 (Dlugokencky et al., 2011), and nine sites of the CSIRO Global Atmospheric Sampling Laboratory (GASLAB), released August 2011 (Francey et al., 1996), which collect air samples distributed globally with an uncertainty of $1.5 \mathrm{ppb}$. Four sites are in both networks: Alert, Canada; Mauna Loa, USA; Cape Grim, Australia; and the South Pole. The flask data from both networks are reported on the NOAA04 mole fraction scale. Figure 1 shows the locations of the 57 ESRL and GASLAB sites used in this work. Only sites that have a continuous record over the study period (June 2009-December 2010) were used in the inversions.

To evaluate the performance of the posterior fluxes we use surface $\mathrm{CH}_{4}$ measurements from the AGAGE (Advanced Global Atmospheric Gases Experiment, June 2012 release) network (Prinn et al., 2000; Cunnold et al., 2002; Chen and Prinn, 2006; Rigby et al., 2008) and total column $\mathrm{XCH}_{4}$ measurements from the TCCON (Total Carbon Column Observing Network, GGG2012, Wunch et al., 2011a). The AGAGE measurements have a precision of $0.075-0.15 \%$ and an accuracy of $0.1-0.2 \%$ (2-4 ppb) (Cunnold et al., 2002). These measurements are reported on the Tohoku University (TU) mole fraction scale, which differs from the NOAA04 scale by $0.03 \%$, approximately $0.5 \mathrm{ppb}$ in a column of $1750 \mathrm{ppb}$ (Dlugokencky et al., 2005). Because this is much smaller 


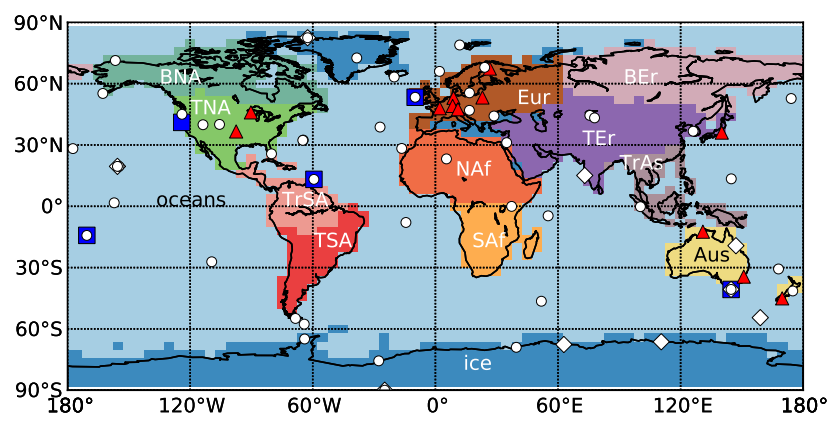

Fig. 1. Geographical location of the 57 co-operative flask sampling sites with data covering the GOSAT data period of June 2009 to December 2010, inclusive (NOAA ESRL sites are white circles, CSIRO GASLAB sites are white diamonds, four sites are part of both networks). Also shown are the measurement sites for the data used in evaluation of the posterior fluxes: AGAGE sites (blue squares) and TCCON sites (red triangles). The 13 regions are informed by previous work (Gurney et al., 2002). The land regions are: Boreal North America (BNA), Temperate North America (TNA), Tropical South America (TrSA), Temperate South America (TSA), North Africa (NAf), South Africa (SAf), Boreal Eurasia (BEr), Temperate Eurasia (TEr), Tropical Asia (TrAs), Australasia (Aus), and Europe (Eur).

than the accuracy of the measurements, we do not adjust the AGAGE measurements to the NOAA04 scale. The TCCON measurements have a precision of $0.2 \%$ and an accuracy of $7 \mathrm{ppb}$ (Wunch et al., 2010). Figure 1 also shows the location of these measurement sites.

\section{The GEOS-Chem transport model}

We use the GEOS-Chem global 3-D chemical transport model (version v8-01-01), driven by version 5 of the assimilated meteorological fields from the NASA Global Modelling and Assimilation Office, to help interpret the GOSAT $\mathrm{XCH}_{4}$ measurements. The model is described and evaluated against surface, aircraft, and satellite measurements of methane in a recent paper (Fraser et al., 2011). In that study we found that the model reproduces the seasonal cycle of methane at the surface and in the free troposphere but overestimates the positive trend over the four year study period. In the stratosphere, the model systematically overestimates methane by $\sim 10 \%$. For this study we use the model with a horizontal resolution of $4^{\circ}$ (latitude) $\times 5^{\circ}$ (longitude) and with 47 vertical levels that span from the surface to the mesosphere with typically 35 levels in the troposphere.

Anthropogenic sources of methane from ruminant animals, coal mining, oil and natural gas production, and landfills are from the Emission Database for Global Atmospheric Research, Fast Track (EDGAR 3.2 FT) inventory (Olivier et al., 2005). These emissions are assumed to have no seasonal variation; year-to-year variation is described using country-specific socio-economic factors (Wang et al., 2004).
Biomass burning emissions are from the Global Fire Emissions Database (GFED v3) inventory, which includes both seasonal and interannual variability (van der Werf et al., 2010). Natural sources from oceans (Houweling et al., 1999), termites, and hydrates are included, as well as a soil sink (Fung et al., 1991). We assume these emissions are constant throughout the study period, though they potentially exhibit yet-to-be described seasonal behaviour. Emissions from rice and wetlands vary seasonally and from year to year, based on a top-down study (Bloom et al., 2012). The tropospheric $\mathrm{OH}$ sink is described by monthly mean 3-D fields generated from a full-chemistry $\mathrm{O}_{\mathrm{x}}-\mathrm{NO}_{\mathrm{x}}-\mathrm{VOC}$ run of the GEOSChem model (Fiore et al., 2003). Loss rates for methane in the stratosphere are adapted from a 2D stratospheric model (Wang et al., 2004). This OH field has been shown to be consistent with observations of methyl chloroform $\left(\mathrm{CH}_{3} \mathrm{CCl}_{3}\right.$, or MCF) from 1990 to 2007 (Patra et al., 2011).

Figure 2 compares GOSAT proxy methane retrievals with $\mathrm{XCH}_{4}$ simulated with the GEOS-Chem model. Unlike the comparisons in Parker et al. (2011), the new comparisons show a regional bias between the data and the model, peaking in the tropics, with GEOS-Chem generally underestimating the GOSAT data. These changes largely reflect revised estimates for wetlands and rice emissions, which take into account changes in the available carbon pool, improving the model's performance with respect to the in situ data (Bloom et al., 2012). Also shown on this figure are the number of measurements in the regions per month from GOSAT.

\section{Ensemble Kalman filter}

We use an ensemble Kalman filter (EnKF) to assimilate the in situ $\mathrm{CH}_{4}$ measurements and $\mathrm{XCH}_{4}$ retrievals and estimate consistent methane fluxes. A detailed description of the EnKF applied to $\mathrm{CO}_{2}$ is given by Feng et al. (2009, 2011). The methane-specific settings for the EnKF are as follows. We do not use a lag window to estimate monthly methane fluxes: measurements of methane only affect fluxes in the month they were taken. Because of model transport error, and unevenly distributed clear-sky observations, in some regions it can be difficult to identify the origin and strength of the emissions correctly. In those regions, using a lag window can introduce likely non-physical changes in the seasonal variation of the fluxes. Fluxes are estimated over the 13 regions (Gurney et al., 2002) shown in Fig. 1. The global ocean is treated as one region. Fluxes are estimated for nine source categories in each of the land regions: wetlands, rice, biomass burning and biofuel, fossil fuels (coal mining and emissions associated with natural gas), ruminant animals, landfills, termites, other emissions (oceans and hydrates), and the soil sink. We assume monthly uncertainties on the prior regional fluxes of $50 \%$ for the categories that vary seasonally (wetlands, rice, and biomass burning) and $25 \%$ for the remaining categories that are assumed to be constant in the model. We 


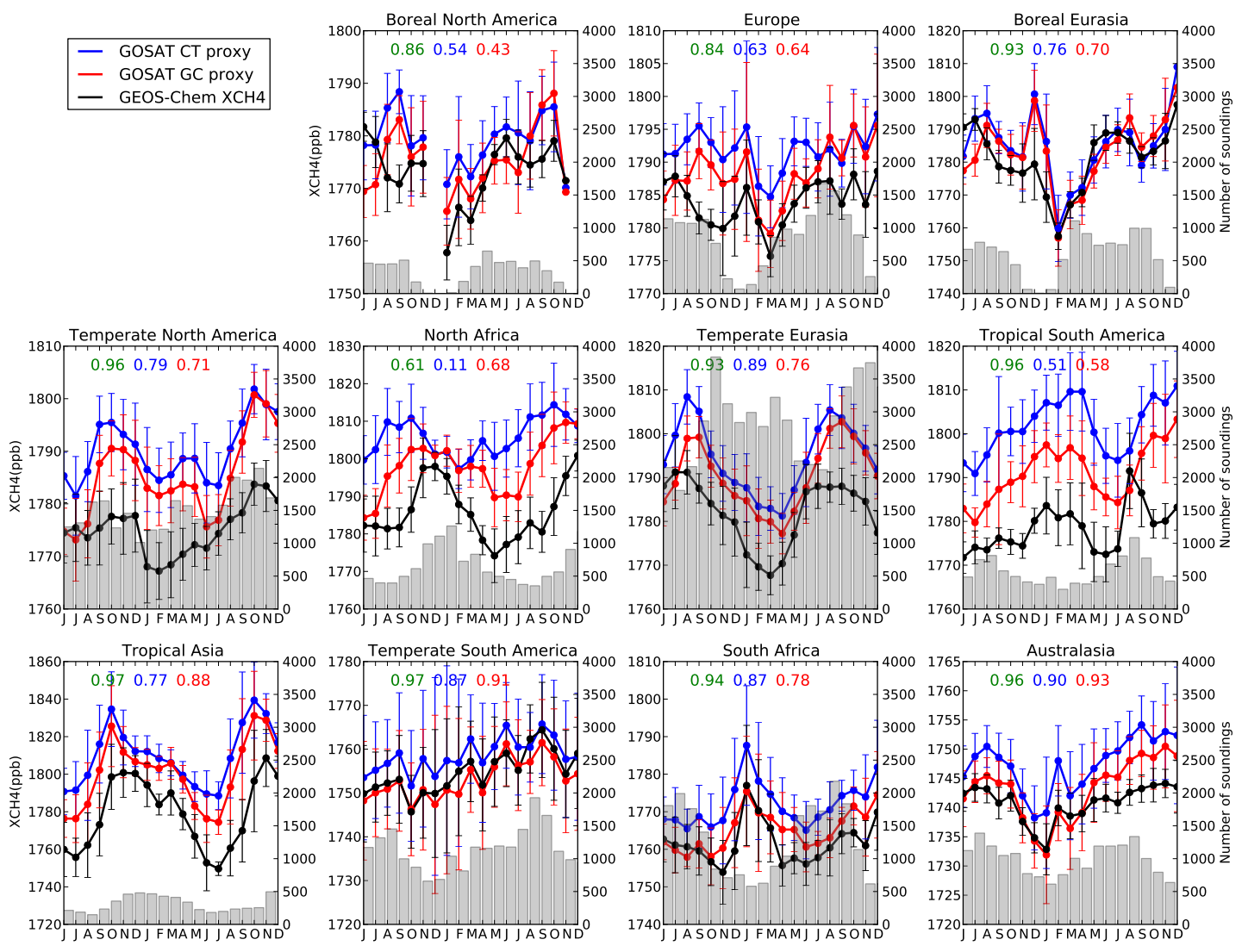

Fig. 2. Time series of the monthly mean GOSAT and GEOS-Chem $\mathrm{XCH}_{4}$ between June 2009 and December 2010 averaged for each of the 11 land regions shown in Fig. 1. The error bars represent one standard deviation of the GOSAT and GEOS-Chem data, respectively. The grey bars are the monthly total number of soundings. The inset numbers are the Pearson correlation coefficients between the two GOSAT proxies (green), the CT proxy and GEOS-Chem $\mathrm{XCH}_{4}$ (blue), and the GC proxy and GEOS-Chem $\mathrm{XCH}_{4}$ (red). Note the different $y$-scales for the $\mathrm{XCH}_{4}$ over each region.

assume uncertainties of $1 \%$ for the ocean region and $10 \%$ for the ice region as these regions have diffuse sources that are unlikely to be informed by the mole fraction data. We assume errors between regions are uncorrelated.

We perform five separate inversions for June 2009December 2010 assimilating:

- INV1: only the surface $\mathrm{CH}_{4}$ measurements

- INV2: only the $\mathrm{XCH}_{4}$ measurements from GOSAT GC proxy

- INV3: both surface $\mathrm{CH}_{4}$ and GOSAT GC proxy $\mathrm{XCH}_{4}$ measurements

- INV4: only the $\mathrm{XCH}_{4}$ measurements from GOSAT CT proxy

- INV5: both surface $\mathrm{CH}_{4}$ and GOSAT CT proxy $\mathrm{XCH}_{4}$ measurements.

In Appendix A we show results from several observing system simulation experiments (OSSEs) that test the ability of the EnKF to retrieve reliable fluxes using the observed distribution of clear-sky GOSAT measurements in the presence of random and systematic errors, giving a theoretical upper limit to the performance of the assimilation system. In these idealized experiments we find that the assimilation scheme is able to retrieve fluxes within $10 \%$ of the known true fluxes in most regions. In tropical regions with few observations and with a large seasonal cycle in the number of measurements, retrieved fluxes are within $15 \%$ of the true fluxes.

Measurements are weighted by their uncertainties in the assimilation. We increase reported uncertainties for the filtered GOSAT $\mathrm{XCH}_{4}$ retrievals by $50 \%$, with resulting values ranging between 9 and $40 \mathrm{ppb}$ with a median value of $14 \mathrm{ppb}$, which is consistent with the standard deviation between GOSAT and TCCON $\mathrm{XCH}_{4}$ (Parker et al., 2011). For the in situ measurements, we adopt the approach taken by Wang et al. (2004): the error is taken to be the sum in quadrature of the transport and representation errors. We describe the transport error as $0.5 \%$ of the mixing ratio obtained by the flask measurement, and the representation error as the standard error of the monthly mean calculated from the 


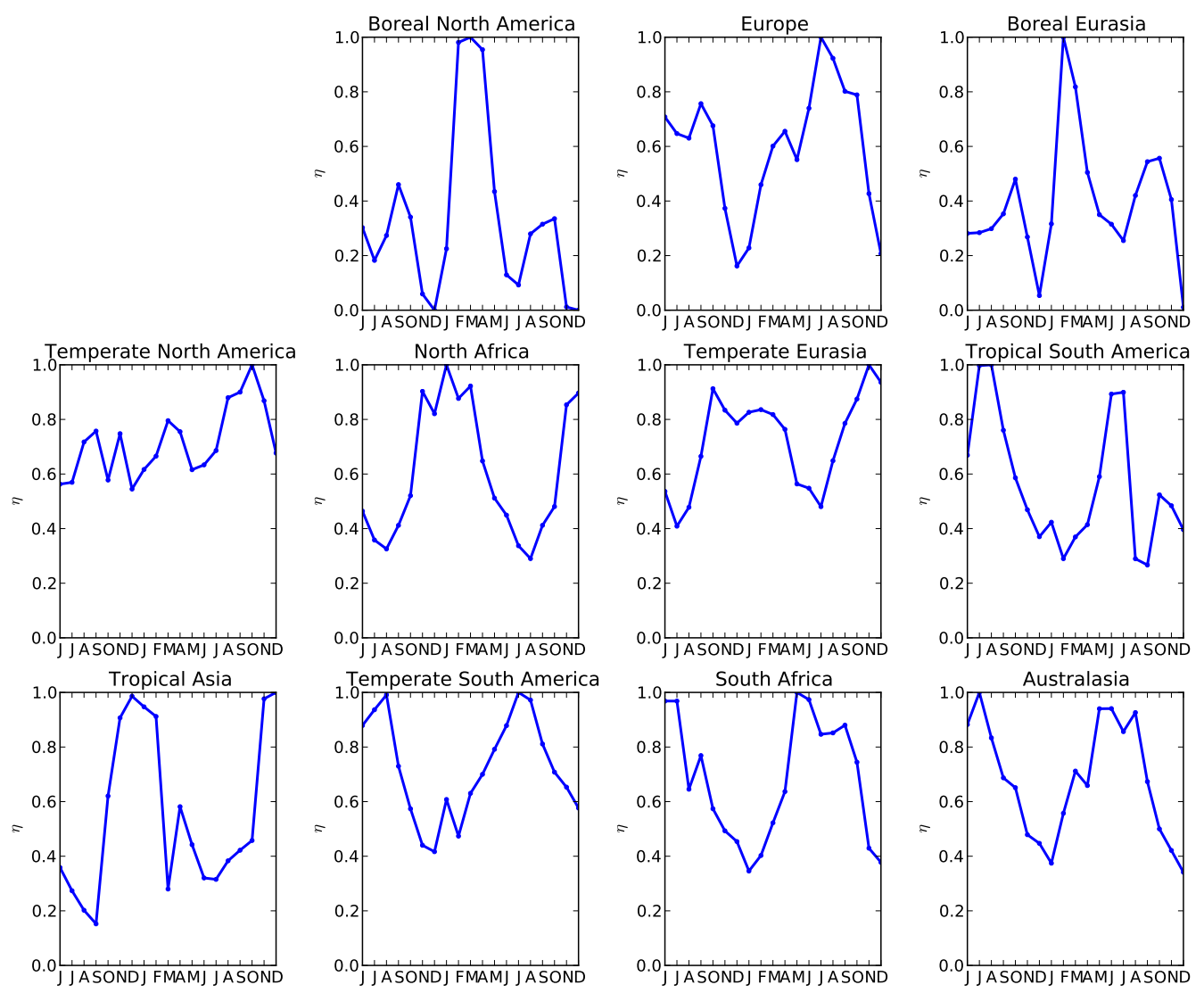

Fig. 3. Time series of the information metric, $\eta$, between June 2009 and December 2010 for each of the 11 land regions shown in Fig. 1.

observations made over that month (Wang et al., 2004). The relatively small measurement uncertainty of approximately $0.1 \%$ ( $1.5 \mathrm{ppb})$ was not considered. The total error typically ranges between 5 and $20 \mathrm{ppb}$, with generally smaller values at Southern Hemisphere stations. Note that the EnKF weights the measurements inversely to their variance (i.e. the square of these total errors).

\subsection{Bias correction}

Similar to $\mathrm{XCO}_{2}$ retrievals, biases in GOSAT $\mathrm{XCH}_{4}$ are expected to be scene dependent, as they are sensitive to, for example, the presence of cirrus clouds and highaltitude aerosols, spectroscopy, airmass, and surface pressure (Wunch et al., 2011b). However, we expect biases from airmass, surface pressure, and aerosol optical depth to be smaller in the proxy $\mathrm{XCH}_{4}$ retrievals than from a full-physics retrieval (Butz et al., 2010). The biases for proxy $\mathrm{XCH}_{4}$ retrievals are further complicated by uncertainties in model $\mathrm{XCO}_{2}$ (Sect. 2) (Schepers et al., 2012). Biases between the model and data can also arise from the model, for example from errors in the transport. For simplicity, we assume that the biases in GOSAT $\mathrm{XCH}_{4}$ data vary only with latitude, following previous studies (Bergamaschi et al., 2009), and are constant over the study period.
From a comparison with prior model simulations, we find that the main features of the systematic difference between the model and GOSAT retrievals can be approximately described by a piecewise linear function with five evenly spaced nodes at latitudes $60^{\circ} \mathrm{S}, 30^{\circ} \mathrm{S}, 0^{\circ}, 30^{\circ} \mathrm{N}$, and $60^{\circ} \mathrm{N}$. The biases at these five nodes are estimated as part of the inversions from comparisons of model simulations with GOSAT (and/or in situ) observations. The prior values of the bias at these nodes are taken from the mean difference between the model and GOSAT data at those latitudes averaged over the study period. The uncertainty of the bias at the nodes is taken to be $5 \mathrm{ppb}$. We find that the retrieved bias estimates are robust and not sensitive to assumed prior values or uncertainties and are consistent with an independent statistical analysis (Appendix B).

\subsection{Information metric}

We define a metric, $\eta$, that gives an indication of how much information can be extracted from the GOSAT observations in a given region in a given month:

$\eta=\frac{\text { obs }_{\mathrm{cs}}}{\mathrm{obs}_{\mathrm{p}}} \div \frac{\sigma_{\text {region }}}{\sigma_{\text {total }}}$ 


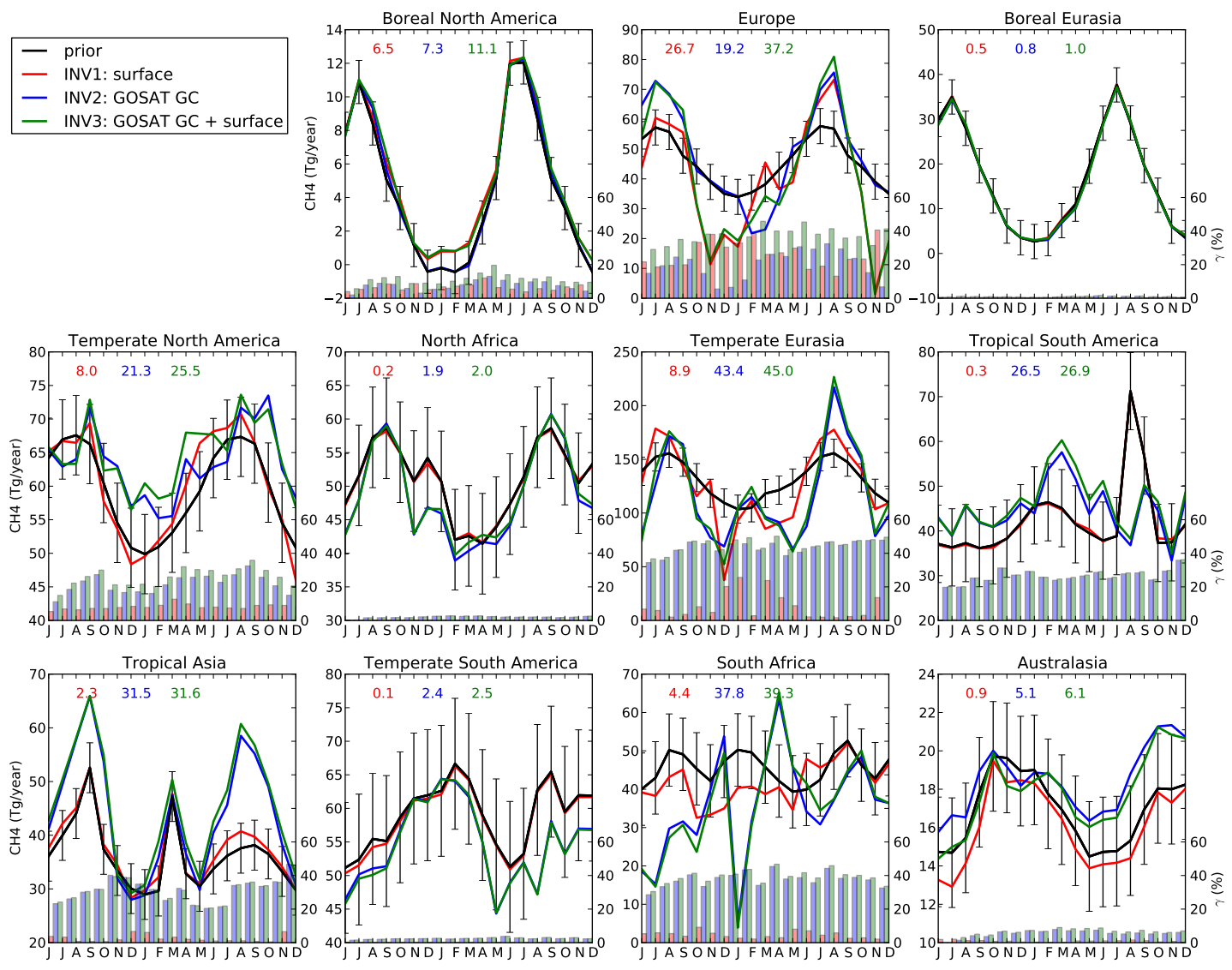

Fig. 4. Monthly prior and posterior flux estimates $\left(\mathrm{TgCH}_{4} \mathrm{yr}^{-1}\right)$ for June 2009-December 2010 for INV1-3 for the land regions shown in Fig. 1. Error bars indicate the error of the prior fluxes. The coloured bars are the monthly percentage error reductions (Eq. 3) for the three inversions. The inset numbers are the mean percentage error reductions for the regions for surface data only (red), GOSAT GC proxy data only (blue), and both surface and GOSAT GC proxy data (green). Note the different $y$-scales for the fluxes.

where obs $\mathrm{cs}_{\mathrm{cs}}$ is the number of clear-sky observations in the region for that month, obs $\mathrm{p}_{\mathrm{p}}$ is the number of possible observations in the region, calculated from the theoretical distribution of measurements for a satellite in the GOSAT orbit, $\sigma_{\text {region }}$ is the standard deviation of the prior fluxes within the region during the month, and $\sigma_{\text {total }}$ is the standard deviation of the total prior flux in the region over the 19-month study period. We normalize $\eta$ to the maximum value in a particular region. When the fraction of clear-sky observations increases, $\eta$ is larger: the more measurements there are the more information contained in them. When the variation of the fluxes within a region as a fraction of the variation of the total flux increases, $\eta$ is smaller: the more variation in the fluxes in a region means that more observations would be needed to fully capture the variation in the region. Figure 3 shows the time series of $\eta$ for the 11 land regions used in this study. All regions display a seasonal cycle in $\eta$. As expected, the boreal regions and Europe have a minimum in the winter when the number of measurements is close to zero. These regions also have the largest peak-to-peak difference. The boreal regions have their maximum values in February or March, reflecting the small variation in fluxes within the regions at that time. Other regions, such as Tropical Asia and South America, show minima when cloud cover is greatest. Temperate North America has the smallest variation, with values of $\eta$ always greater than 0.5 . We do not define a "cutoff" below which we do not analyse data, but note that lower values of $\eta$ denote months where we have less confidence in the inversion results within that region. Because the metric is only dependent on the number of observations and the variation within an individual region, and other factors that would influence the information content of the region are not explicitly included, values of $\eta$ within one region cannot be directly compared to values of $\eta$ in other regions.

\section{Results}

\subsection{Posterior fluxes}

Table 1 shows the average prior and posterior fluxes for the five inversions over each of the 11 land regions and sector categories and averaged over the study period 
Table 1. Mean prior and posterior fluxes for the land regions and source categories in $\mathrm{TgCH}_{4} \mathrm{yr}^{-1}$. The total global values represent the sum of the land regions and contribution from the ocean $\left(17.9 \pm 0.2 \mathrm{TgCH}_{4} \mathrm{yr}^{-1}\right)$ and ice $\left(3.1 \pm 0.3 \mathrm{TgCH}_{4} \mathrm{yr}^{-1}\right) \mathrm{regions}$.

\begin{tabular}{|c|c|c|c|c|c|c|c|c|c|c|c|c|}
\hline \multirow[b]{2}{*}{ Region } & \multicolumn{2}{|c|}{ Prior } & \multicolumn{2}{|c|}{ INV1: surface } & \multicolumn{2}{|c|}{ INV2: GC } & \multicolumn{2}{|c|}{ INV3: GC + surf. } & \multicolumn{2}{|c|}{ INV4: CT } & \multicolumn{2}{|c|}{ INV5: CT + surf. } \\
\hline & flux & error & flux & error & flux & error & flux & error & flux & error & flux & error \\
\hline Boreal North America & 4.5 & 1.3 & 5.1 & 1.2 & 4.6 & 1.2 & 5.1 & 1.1 & 4.5 & 1.2 & 5.1 & 1.1 \\
\hline Europe & 45.5 & 5.9 & 40.0 & 4.3 & 48.4 & 4.8 & 41.9 & 3.7 & 43.9 & 4.8 & 39.6 & 3.7 \\
\hline Boreal Eurasia & 16.7 & 3.8 & 16.8 & 3.8 & 16.4 & 3.8 & 16.5 & 3.8 & 16.3 & 3.8 & 16.5 & 3.8 \\
\hline Temperate North America & 59.5 & 5.9 & 60.3 & 5.4 & 63.4 & 4.7 & 64.6 & 4.4 & 61.9 & 4.7 & 62.5 & 4.4 \\
\hline North Africa & 51.0 & 7.5 & 50.9 & 7.5 & 48.6 & 7.3 & 48.9 & 7.3 & 47.0 & 7.4 & 46.9 & 7.3 \\
\hline Temperate Eurasia & 130.8 & 13.1 & 125.3 & 12.0 & 116.1 & 7.4 & 118.7 & 7.2 & 115.4 & 7.5 & 115.9 & 7.3 \\
\hline Tropical South America & 42.2 & 8.6 & 42.3 & 8.6 & 44.7 & 6.3 & 46.1 & 6.3 & 49.2 & 6.4 & 49.6 & 6.4 \\
\hline Tropical Asia & 36.2 & 4.6 & 37.3 & 4.5 & 43.4 & 3.2 & 45.0 & 3.2 & 42.3 & 3.2 & 43.5 & 3.2 \\
\hline Temperate South America & 58.9 & 9.8 & 58.5 & 9.7 & 54.8 & 9.5 & 54.6 & 9.5 & 56.0 & 9.5 & 55.8 & 9.5 \\
\hline South Africa & 45.5 & 9.4 & 41.6 & 9.0 & 35.7 & 5.9 & 35.7 & 5.7 & 37.6 & 5.9 & 36.6 & 5.8 \\
\hline Australasia & 16.9 & 2.9 & 16.1 & 2.8 & 18.5 & 2.7 & 17.8 & 2.7 & 18.4 & 2.7 & 17.6 & 2.7 \\
\hline Category & flux & error & flux & error & flux & error & flux & error & flux & error & flux & error \\
\hline Animals & 91.3 & 6.0 & 90.0 & 5.6 & 91.1 & 3.7 & 91.4 & 3.6 & 90.3 & 3.7 & 90.0 & 3.6 \\
\hline Fossil fuel & 89.3 & 7.2 & 88.2 & 6.6 & 75.3 & 4.8 & 76.7 & 4.6 & 74.2 & 4.8 & 74.6 & 4.6 \\
\hline Landfill & 43.0 & 3.4 & 42.5 & 2.9 & 43.4 & 2.7 & 43.0 & 2.4 & 42.8 & 2.7 & 42.5 & 2.4 \\
\hline Biomass burning & 19.5 & 2.3 & 19.6 & 2.2 & 18.3 & 1.6 & 18.6 & 1.6 & 18.1 & 1.6 & 18.3 & 1.6 \\
\hline Rice & 70.8 & 11.0 & 66.5 & 10.0 & 70.1 & 5.9 & 70.9 & 5.7 & 70.0 & 5.9 & 69.5 & 5.8 \\
\hline Wetlands & 191.1 & 19.3 & 184.2 & 18.7 & 193.8 & 16.4 & 191.5 & 16.1 & 195.0 & 16.5 & 192.1 & 16.1 \\
\hline Oceans and hydrates & 8.2 & 0.4 & 8.2 & 0.4 & 8.2 & 0.4 & 8.3 & 0.4 & 8.2 & 0.4 & 8.3 & 0.4 \\
\hline Termites & 19.5 & 1.0 & 19.5 & 1.0 & 19.4 & 0.8 & 19.4 & 0.8 & 19.3 & 0.8 & 19.3 & 0.7 \\
\hline Soil sink & -24.8 & 1.3 & -24.7 & 1.2 & -25.0 & 1.0 & -24.9 & 1.0 & -25.1 & 1.0 & -25.0 & 1.0 \\
\hline Total global & 528.8 & 24.6 & 515.0 & 23.3 & 515.7 & 18.8 & 516.1 & 18.3 & 513.8 & 18.8 & 510.6 & 18.4 \\
\hline
\end{tabular}

June 2009-December 2010. The results from the ice and ocean regions are not shown as the emissions from these regions are small compared to the land regions and do not vary significantly from the prior. The total global fluxes from all the inversions agree with the prior amount of $529 \pm$ $25 \mathrm{Tg} \mathrm{yr}^{-1}$, but are $13-19 \mathrm{Tg} \mathrm{yr}^{-1}$ smaller: between 510 $516 \mathrm{Tg} \mathrm{yr}^{-1}$.

We define a percentage error reduction metric $\gamma$ :

$\gamma=\left[1-\frac{\epsilon}{\epsilon_{0}}\right] \times 100 \%$,

where $\epsilon$ is the posterior flux error, and $\epsilon_{0}$ is the prior flux error. $\gamma$ is defined such that larger values indicate that more information has been extracted from the observations (Feng et al., 2011; Palmer et al., 2011).

The posterior flux errors are generally smaller for the inversions using GOSAT data (INV2-5): the mean $\gamma$ for the surface only inversion (INV1) is $6.0 \%$, while for the inversions using GOSAT data $\gamma$ ranges from $17-20 \%$. This reflects information content from a much larger number and distribution of measurements than from the surface network. Europe is the only exception: this region has a reasonable surface measurement density on the spatial scale of the inversions, with six stations within the region and several more in the surrounding area. Recent results for a $\mathrm{CO}_{2}$ inversion also concluded that Europe is well-sampled by the sur- face network (Niwa et al., 2012). Also due to GOSAT's orbit, high latitude Europe is not observed though the winter (November-February at $50^{\circ} \mathrm{N}$ ), allowing the surface data to have more influence than the satellite data during these months. The largest changes are found in Temperate Eurasia and Tropical Asia (Fig. 1). Fluxes over Boreal North America and Eurasia are largely unaffected by GOSAT data, which is expected as the majority of these regions lie north of the $60^{\circ}$ latitude filter we apply to the GOSAT data (Sect. 2).

The total posterior fluxes of the source categories are typically within $5 \%$ of the prior fluxes, however the associated uncertainties have been reduced by $9-48 \%$ after the GOSAT data are assimilated. Only fossil fuel emissions change by more than the prior uncertainty, with emissions from the inversions using the GOSAT data (INV2-5) reduced by 34 $36 \%$. Typically, assimilating the surface and GOSAT data moves the posterior fluxes in the same direction (becoming larger or smaller than the prior), however wetland emissions become smaller using only the surface data (INV1) and larger in the four inversions using the GOSAT data (INV2-5).

Figure 4 shows the time series of the monthly regional prior and posterior methane flux estimates over the study period inferred from surface data only, GOSAT GC proxy data only, and surface and GOSAT GC proxy data (INV1-3). Similar results using the CT proxy data are shown in Fig. C1 in Appendix C. In general the inversion using only surface 
data (INV1) is consistent with the prior flux emissions. The posterior fluxes over Temperate North America, Eurasia, and Europe show shifts in the seasonal cycle and changes in the peak emissions relative to the prior. The seasonal cycle of methane fluxes over South Africa changes significantly, due primarily to changes in wetland emissions. Also shown in Fig. 4 is the monthly error reduction $(\gamma)$ from the three inversions (coloured bars) and the mean error reduction over the whole time period. The mean error reductions for INV1, with the exception of Europe, are all less than $25 \%$.

In general for non-boreal regions, GOSAT $\mathrm{XCH}_{4}$ retrievals increase $\gamma$, resulting in posterior fluxes that are statistically different from the prior. Over South America, South Africa, Tropical Asia, and Australasia, where surface measurements are sparse and therefore provide weak constraints, GOSAT observations have the largest impact on the error reduction with values at least three times as large as those for the surface inversions. For these regions the posterior fluxes generally follow the same seasonal cycle as the prior, with changes only in the magnitude of the fluxes. Europe, as discussed above, is the one region where more information comes from the surface than the satellite observations on our spatial scale.

The largest seasonal departures between the posterior and the prior are over Temperate North America and South Africa. In Temperate North America the GOSAT data are implying a smaller amplitude in the seasonal cycle of the methane emissions. For South Africa this is partly a result of the performance of the inversions in this region: the seasonal cycle of the observations, due to clouds and aerosols, leads to uneven seasonal sampling. As discussed previously, the OSSEs highlighted an upper limit of $11 \%$ for inferring true fluxes over this region due to GOSAT sampling (Appendix A). This region is further discussed below.

\subsubsection{South Africa}

The posterior fluxes in South Africa from the GC and CT proxies differ, especially in January when the GC proxy flux drops to nearly zero. This difference is due to CarbonTracker's larger $\mathrm{XCO}_{2}$, and hence $\mathrm{XCH}_{4}$, columns in the region. The sharp drop in fluxes in January using the GC proxy is caused by a sharper latitudinal gradient in the GC proxy than the GOSAT $\mathrm{XCH}_{4}$. This region is often covered by cirrus clouds at this time of year (Heymann et al., 2012), which may not be filtered out by the cloud filtering applied in the GOSAT retrievals. Schepers et al. (2012) compare retrievals of $\mathrm{XCH}_{4}$ using both the proxy method and a "full physics" method, which explicitly models atmospheric scattering processes. The full physics retrieval returns several parameters to describe the scattering, or path length, through the atmosphere, including aerosol optical thickness, height of the aerosol layer, and a size parameter. Schepers et al. (2012) show that although the proxy method is less sensitive to these scattering parameters than the full physics method, some de- pendence remains, with columns underestimated by $>1 \%$ $(\sim 17.5 \mathrm{ppb}$ in a column of $1750 \mathrm{ppb})$ for large scattering path lengths. The proxy method does not return any estimates of scattering, so we have investigated three parameters that are retrieved to identify outlying data that may be affected by scattering, either by cirrus clouds or aerosols: the ratio of the model and retrieved $\mathrm{CO}_{2}$, differences in prior and posterior surface pressure, and differences in retrieved brightness temperature at several levels in the vertical profile. None of these parameters are correlated with the location of cirrus clouds, and filtering for outlying values of these parameters has no significant effect on the posterior fluxes.

We also attempted to filter for the aerosol optical depth (AOD) retrieved by the full physics $\mathrm{XCO}_{2}$ retrieval product from the Atmospheric $\mathrm{CO}_{2}$ Observations from Space (ACOS) group (Crisp et al., 2012). We matched the proxy $\mathrm{XCH}_{4}$ retrievals to the $\mathrm{XCO}_{2}$ retrievals and filtered using the recommended value for the ACOS product: 0.15 (Crisp et al., 2012), which eliminated roughly $25 \%$ of the available data. The results of the inversion using this filter on the GC proxy data and assimilating the surface data are shown in Fig. 5. The fluxes are generally not significantly changed in the region, with the exception of the sharp drop in January 2010, which is reduced. The data that is excluded by the filter is affected by a large AOD, and could potentially be biased low, as per Schepers et al. (2012).

The standard inversion only allows measurements to affect the fluxes in the month that they were taken, however methane has a lifetime of $\sim 10 \mathrm{yr}$ in the atmosphere. We increased the lag window to three months, so that measurements can affect monthly fluxes up to three months before or after they are taken. The results of this are also shown in Fig. 5. This has the effect of slightly increasing the drop in the flux in January 2010, and generally reducing the fluxes throughout the whole time period.

Finally we separated the South African region into three roughly equal area regions by latitude and ran the inversion. In this experiment, the posterior fluxes in the southern-most region stayed close to the prior, while those in the other two regions varied. The results of this are also shown in Fig. 5, with the three regions re-combined into one. The posterior fluxes in general stay closer to the prior and the sharp drop in January is removed. However, the fluxes in other regions influenced by South Africa are negatively affected. In North Africa and South America the fluxes are decreased and display unphysical variation.

As shown by the OSSEs discussed in Appendix A, the EnKF does not perform as well in South Africa as in other regions. That, combined with the sensitivity to AOD highlighted by the ACOS AOD filtering experiment, leads to posterior fluxes that are not always reliable. The value of $\eta$ (Sect. 4.2) in the region is at a minimum in January, at the time of the drop, meaning that the information contained in the GOSAT data is at a minimum at this time. 


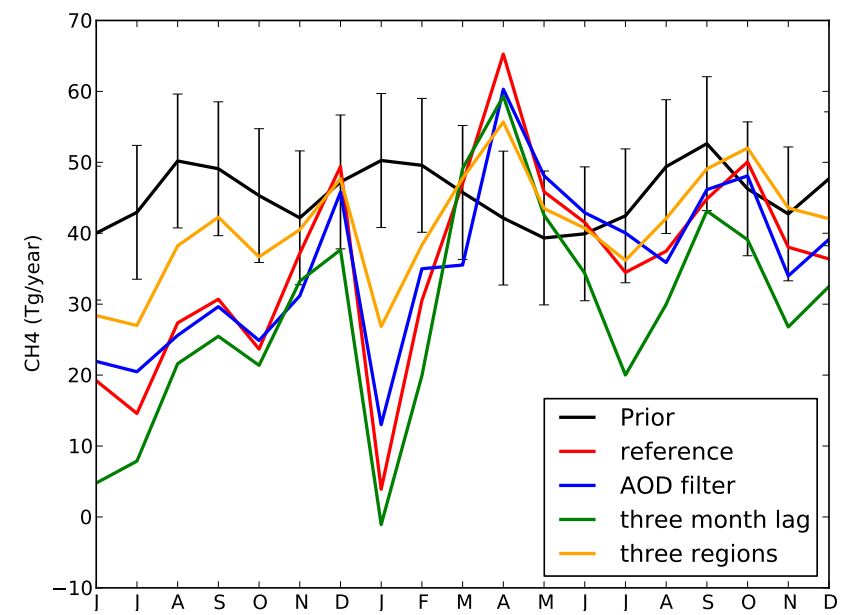

Fig. 5. Monthly prior and posterior flux estimates $\left(\mathrm{TgCH}_{4} \mathrm{yr}^{-1}\right)$ for the South African region assimilating the GC proxy and surface data and the effect of filtering by parameters related to aerosols and cirrus clouds, changing the lag window of the EnKF, and splitting the region into three regions.

\subsection{Agreement with ground-based data}

To assess the performance of the model's posterior fluxes, we force the GEOS-Chem model with the posterior fluxes described in Sect. 5.1. To avoid inconsistencies in the fluxes and resulting concentrations, we first "spin-up" the model for $4.5 \mathrm{yr}$, from January 2005, using posterior fluxes from January to December 2010 and the appropriate GEOS-5 meteorology. Figure 6 shows daily mean and hemispherically averaged GEOS-Chem (prior and INV3 posterior fluxes) and observations for two other ground-based methane measurement networks (Sect. 2): AGAGE (surface mole fraction, June 2012 release) and TCCON (total column mole fraction, GGG2012). We have sampled the model at the time and location of the measurements and for the TCCON sites we have smoothed the GEOS-Chem profile using TCCON averaging kernels and a priori. Figure 6 also shows the mean bias and standard deviation of the differences between the observations and the model, and the correlation coefficient $\left(r^{2}\right)$ between the observations and model. For both AGAGE and TCCON comparisons the effects of the posterior emissions are greatest in the Northern Hemisphere, where the largest changes in the emissions occur. In the Northern Hemisphere the posterior standard deviations are 1-2 ppb smaller and the posterior correlations are larger (by 0.09 and 0.18 , respectively) than the prior values while the biases are increased by approximately $1 \mathrm{ppb}$ for AGAGE and decreased by $2 \mathrm{ppb}$ for TCCON. For the Southern Hemisphere AGAGE comparisons, the posterior standard deviation is increased by $0.2 \mathrm{ppb}$ and the correlation coefficient is decreased by 0.03 while the biases are decreased by $9.1 \mathrm{ppb}$. At TCCON sites, the bias decreases by $1.7 \mathrm{ppb}$ and the standard deviation decreases by $1.6 \mathrm{ppb}$, while the correlation coefficient increases by 0.03 . In all cases, the absolute biases are decreased from the prior to the posterior. The GC proxy posterior fluxes have the greatest impact on the AGAGE $\mathrm{CH}_{4}$ comparison, as expected because, in the short term, changes in the emissions will affect the surface mole fractions more than the total column abundance due to the time taken to transport methane emitted at the surface upwards from the boundary layer to the free troposphere. Differences between the prior and the four inversions using GOSAT data are similar, while the surface-only inversion remains closer to the prior model (not shown).

Figure 7 shows the correlation coefficient $\left(r^{2}\right)$ and absolute mean difference between the model (driven by prior and posterior flux estimates from the five inversions) and observations at the 5 AGAGE sites and the 12 TCCON sites used in this study. For the AGAGE $\mathrm{CH}_{4}$ data, all the inversions improve the correlation between the observations and the model relative to the prior at sites in the Northern Hemisphere and decrease the correlation at sites in the Southern Hemisphere. Co-located AGAGE and ESRL measurements have been shown to agree within $1 \mathrm{ppb}$ and to have similar precisions, so we expect that assimilating the ESRL and GASLAB data should improve the agreement with the AGAGE data. In addition, the AGAGE stations are co-located with ESRL and GASLAB measurement sites (or located close to, in the case of Trinidad Head) which are assimilated in our inversions. However, AGAGE measurements are continuous, while ESRL and GASLAB measurements are weekly and at many sites samples are taken when the wind is from a nonpolluted direction (e.g. at Cape Grim, Australia only when the winds are coming from the Southern Ocean). AGAGE measurements collect data from all directions, meaning that they are more influenced by local emissions than the ESRL and GASLAB measurements, which are designed to sample background airmasses. The biases between the observations and model values decrease for Mace Head, Ragged Point, and Cape Grim and increase at Trinidad Head and Samoa. On average, the bias is decreased by $1.1 \mathrm{ppb}$ across all sites.

Karlsruhe, Wollongong, and Lauder are the only TCCON sites where the model reproduces most of the observed variability, with $r$-squared values greater than 0.5 . At the other sites, neither the prior or posterior models reproduce the variability in the observations (i.e. $r$-squared values are smaller than 0.5). Using the posterior fluxes from all inversions improves the correlation coefficient between TCCON observations and the model, with the exception of Karlsruhe and Darwin. At Karlsruhe, correlation coefficients are increased when only GOSAT data is assimilated, but decrease when surface data are included. This mixed performance is perhaps due to the shorter time series available at Karlsruhe where measurements are available from April 2010. At Darwin correlation coefficients are consistently smaller using the posterior data. At Wollongong the $r$-squared values are mostly unchanged. Biases between the TCCON XCH${ }_{4}$ columns and the model can either increase or decrease, depending on the 

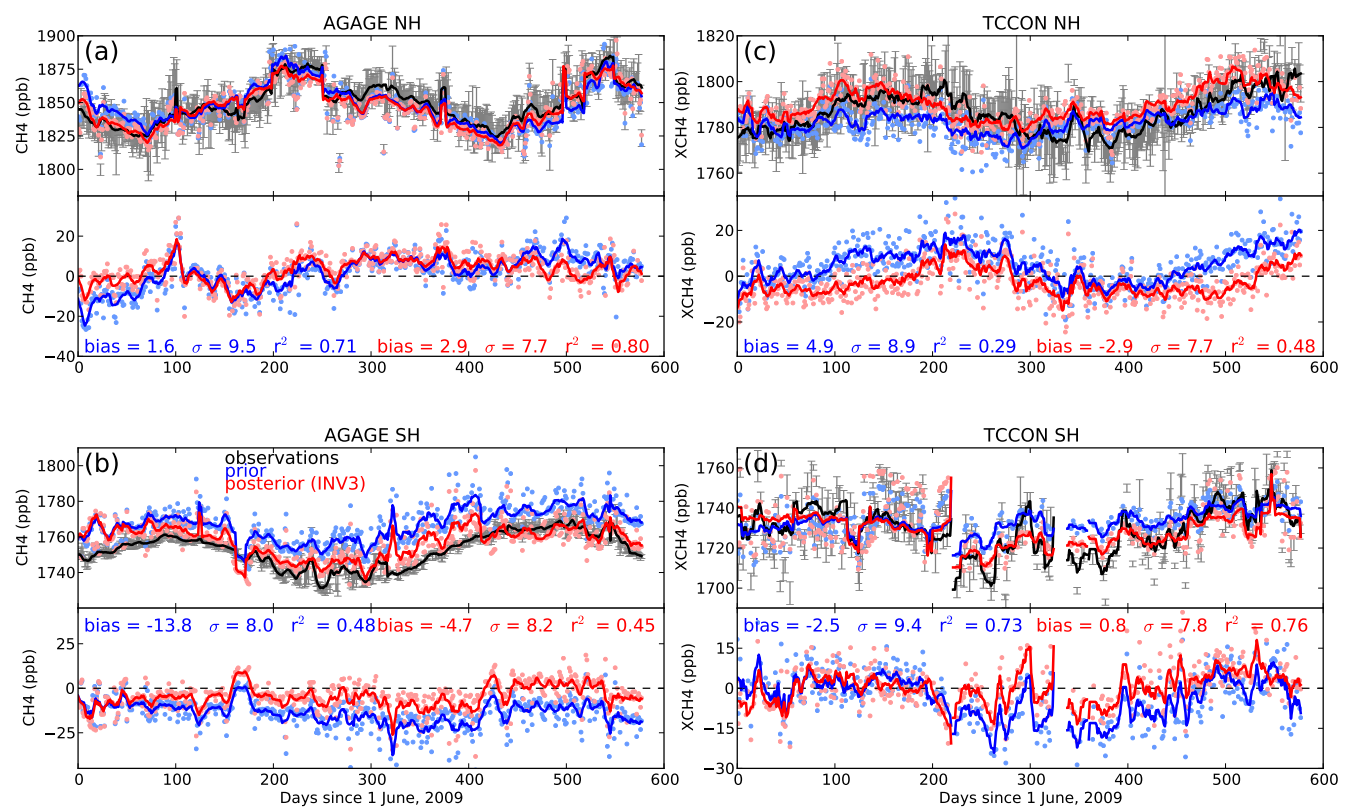

Fig. 6. (a) Top panel: time series of daily averaged surface $\mathrm{CH}_{4}$ observations (ppb) from the AGAGE network and corresponding model values with prior and posterior (INV3, GC proxy and surface data) emissions. Values have been averaged over the Northern Hemisphere $(\mathrm{NH})$. Grey error bars on the observations represent one standard deviation of measurements used in the hemispheric average. The light coloured dots are the individual daily values while the lines are a seven-day running mean. Bottom panel: the time series of the difference (observations-model). The prior (blue) and posterior (red) bias and standard deviation of the difference between the measurements and model are given on the figure (in ppb), as well as the correlation coefficient. (b) As (a) but for the Southern Hemisphere (SH). (c) As (a) but for total column $\mathrm{XCH}_{4}$ observations (ppb) from the TCCON network. (d) As (c) but for the SH.
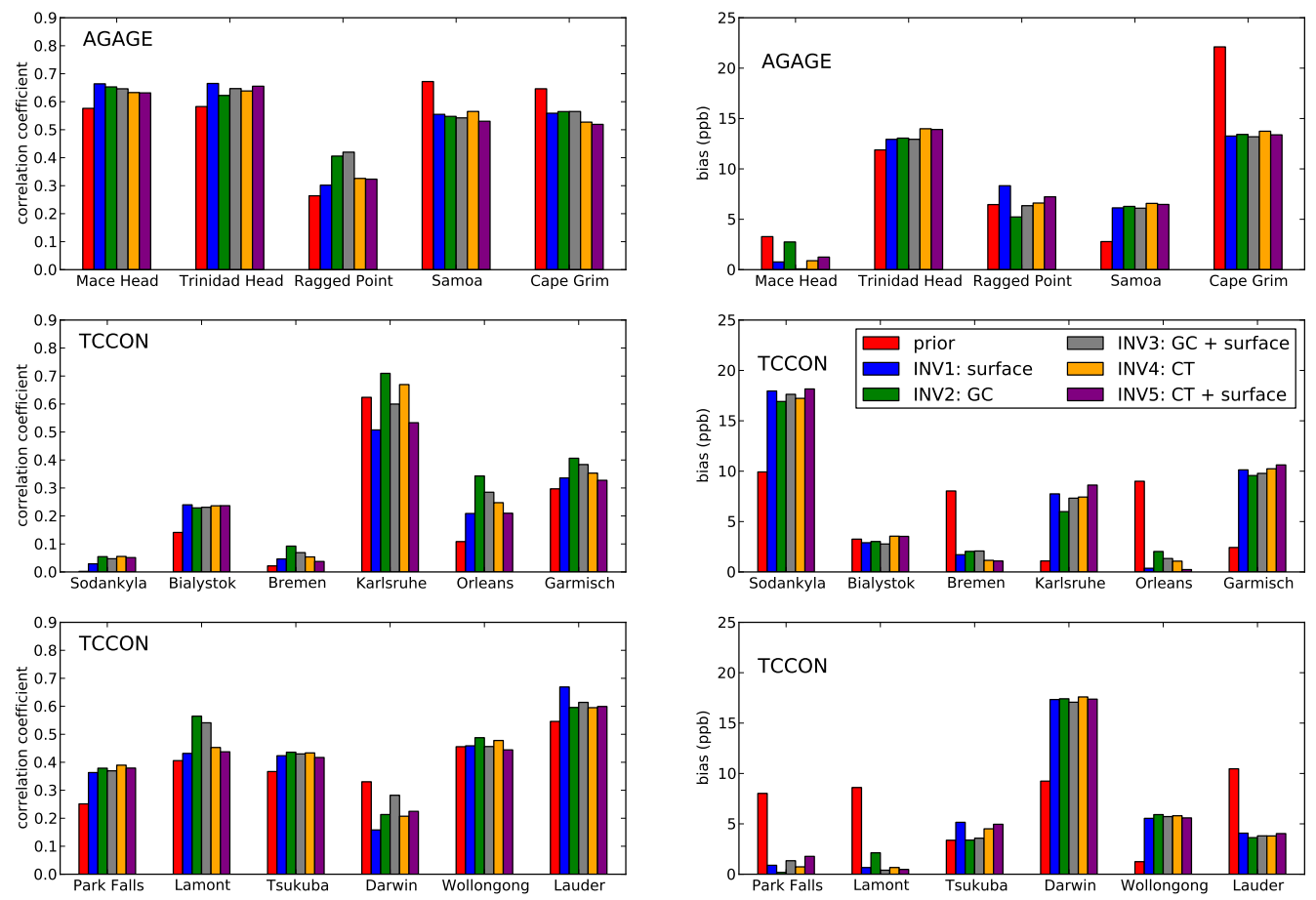

Fig. 7. Left panels: correlation coefficients $\left(r^{2}\right)$ between the observations and prior and posterior models at the 5 AGAGE sites (top panel) and 12 TCCON sites (middle and bottom panel) used in this work. Right panels: absolute value of the mean of the bias between the observations and prior and posterior models at the AGAGE and TCCON sites. 
site. On average, the bias is decreased by $0.1 \mathrm{ppb}$ across all sites.

The mixed performance of the posterior fluxes in the Southern Hemisphere is a result of the trends at Southern Hemisphere sites. At Northern Hemisphere sites, the difference between the prior and posterior fluxes shows a seasonal cycle, but no strong trend at either AGAGE or TCCON sites. In the Southern Hemisphere, this difference is increasing at all sites from both networks. This is visible in the bottom panels of Fig. $6 \mathrm{~b}$ and d, as the differences between the model and data diverge over time. At the relatively clean-air sites of Cape Grim and Lauder, the bias is significantly decreased as the posterior model approaches the data, but the $r$-squared value is reduced at Cape Grim as the amplitude of the seasonal cycle of the posterior model is reduced by the changes in the fluxes. At the tropical sites of Samoa and Darwin, interhemispheric transport (e.g. Fraser et al., 2011) may also have a complicating role.

Looking at both AGAGE and TCCON sites together, the biases within continents tend to both increase and decrease. For example, at European sites four sites see an improvement in the bias, while at three sites the bias increases. Similar patterns are seen in Australasia and Temperate North America. As shown by the OSSEs (Appendix A), the ensemble Kalman filter is able to retrieve continental-scale fluxes. The resolution of the Kalman filter is not fine enough to universally improve the comparisons with individual sites within these diverse continental regions.

\section{Concluding remarks}

We have used an EnKF to estimate regional methane fluxes using two different proxy $\mathrm{XCH}_{4}$ GOSAT datasets and weekly surface ESRL and GASLAB $\mathrm{CH}_{4}$ data and evaluated the results using AGAGE $\mathrm{CH}_{4}$ and TCCON $\mathrm{XCH}_{4}$ measurements. The posterior global flux of each inversion agrees with the prior value of $529 \pm 25 \mathrm{Tg} \mathrm{yr}^{-1}$, but is consistently smaller: between $510-516 \mathrm{Tg} \mathrm{yr}^{-1}$. Changes in total emissions and seasonal cycle are seen at the regional level. The largest changes occur in Temperate Eurasia (a decrease) and Tropical Asia (an increase) due to changes in emissions from rice cultivation. Despite the shift in rice emissions to lower latitudes, the total rice emissions remain the same as the prior. The posterior fluxes from the GC and CT proxy agree, with differences reflecting initial differences in the $\mathrm{XCH}_{4}$ values, and hence differences in the modelled $\mathrm{XCO}_{2}$. In all inversions there is significant month-to-month variation in the retrieved fluxes in some regions (e.g. Temperate North America), which may be improved by introducing temporal correlation to the posterior fluxes in the EnKF.

We have used the posterior fluxes from the inversions in GEOS-Chem and compared to ground-based measurements of surface $\mathrm{CH}_{4}$ (AGAGE) and total column $\mathrm{XCH}_{4}$ (TCCON) measurements. As expected, the difference between the prior and posterior model was greater at the AGAGE sites since the surface concentration makes up only a portion of the total column. As a result, changes in methane emissions are detectable earlier at the surface than in the total column. At the AGAGE sites, which are co-located with assimilated ESRL and GASLAB sites, assimilating the surface and/or GOSAT data increases the correlations at Northern Hemisphere sites and decreases the correlations at Southern Hemisphere sites. At the TCCON sites, assimilating the data tends to increase the correlation coefficients but the bias can be either increased or decreased. In all cases, the changes in bias and $r$-squared are modest.

While the surface data do constrain methane emission estimates, the limited spatial coverage leaves large areas of the globe with no measurements. For example, tropical and Southern Asia, the regions with the largest methane emissions, have only two surface sites in India and Indonesia to constrain the emissions. GOSAT observations cover a larger geographical area than surface observations and hence provide more information to the assimilation system. The error reductions for inversions using GOSAT data are at least twice the error reductions when only surface data are assimilated with the exception of the boreal regions, where we filter the GOSAT data, and Europe, which is well covered by the surface network. However, surface data are integral to the inversions as the data from these networks, with a record dating back to the early 1980s, have been validated extensively, while the GOSAT data have so far not undergone such an extensive validation, with many regions of the world (e.g. South America) lacking any TCCON sites for validation. The surface data also contain a stronger signature from the emissions than the total column amounts from GOSAT.

In future studies, we plan to estimate fluxes on a finer spatial scale over select regions, for example resolving the diverse region of Temperate Eurasia on the model grid scale $\left(4^{\circ} \times 5^{\circ}\right)$. This will give more information about the fluxes in the regions, and also potentially improve the results over problematic regions limited by the current assimilation system (such as South Africa). Increasing the resolution of the inversions could also potentially help in improving the comparisons to the TCCON and AGAGE networks. We also plan to assimilate columns of methane from the Infrared Atmospheric Sounding Interferometer (IASI), which are sensitive to the middle troposphere (Razavi et al., 2009). IASI columns could help to constrain the free troposphere, allowing the GOSAT measurements to better inform the surface emissions.

\section{Appendix A}

\section{Observing system simulation experiments}

We performed a series of observing system simulation experiments (OSSEs) using GOSAT data simulated from the 

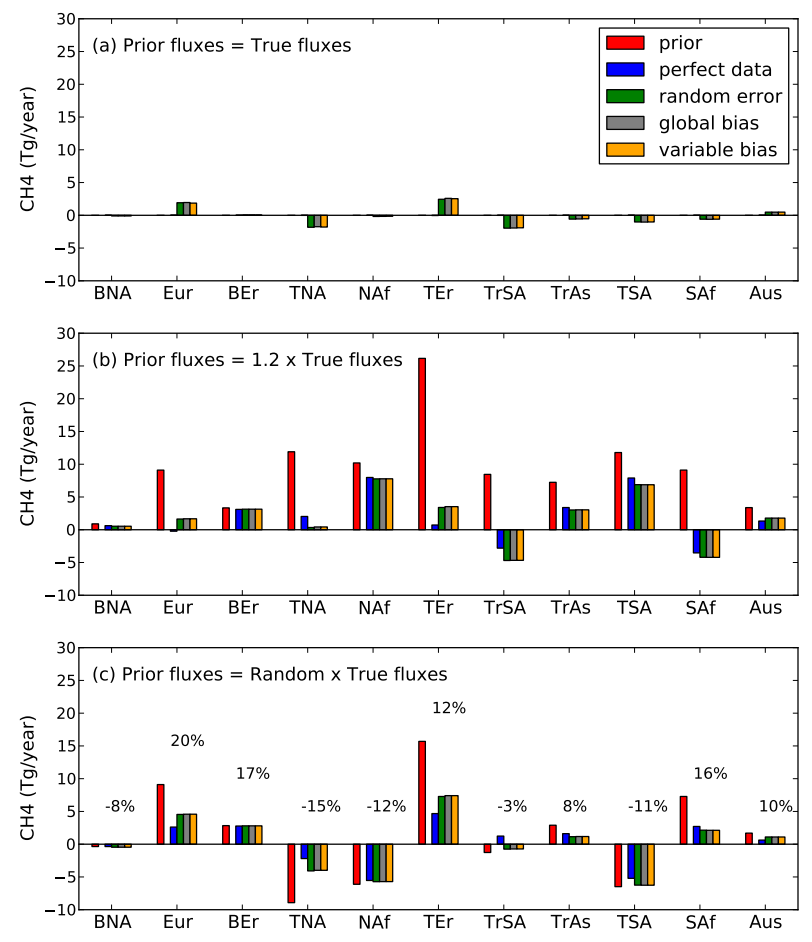

Fig. A1. Difference between prior and posterior fluxes and the true fluxes from the OSSEs performed with data simulated from the model with different types of random and systematic error. (a) Experiments where the prior and true fluxes are equal. (b) Experiments where the prior flux is $20 \%$ larger than the true fluxes. (c) Experiments where the true fluxes are adjusted by a random percentage to form the prior fluxes. The inset numbers above the bars in this subfigure are the initial perturbations to the prior fluxes.

GEOS-Chem model to test the performance of the ensemble Kalman filter using clear-sky atmospheric measurements of $\mathrm{XCH}_{4}$ sampled by the GOSAT instrument, following Feng et al. (2009). We simulated data by sampling the GEOSChem model at the location of the clear-sky GOSAT observations. Four sets of simulated data were created: "perfect data" where the model value is taken as the simulated data, "random error" where we added a randomly generated error to the model based on the error of the actual GOSAT measurement and assuming a Gaussian distribution (Feng et al., 2009), "global bias" where in addition to the random error we added a global bias of $10 \mathrm{ppb}$, and "varying bias" where in addition to the random error we added a latitudinally varying bias with minima at the poles $(-5 \mathrm{ppb})$ and a maximum at the equator $(15 \mathrm{ppb})$. The different simulated datasets will allow us to test our ability to retrieve fluxes with different types of error.

In the first round of experiments, the inversions were run using the same set-up as described in Sect. 4. The model used in the inversion and the model used in generating the data were identical: the prior emissions corresponded exactly to the true emissions used in simulating the data. These ex- periments establish a theoretical upper limit to the assimilation system due to the non-uniform sampling of GOSAT. In these experiments the posterior fluxes retained the seasonal cycle of the true/prior emissions. The annual mean posterior fluxes are shown in Fig. A1a. With "perfect data" the posterior fluxes are within $0.02 \%$ of the true/prior fluxes. The different bias simulations had no significant effect on the posterior fluxes, which are within $5 \%$ of the true/prior fluxes, with the largest differences in Europe and Tropical South America. In all cases, the returned bias was within $1.3 \mathrm{ppb}$ of the true value.

In the second round of experiments, the set-up was identical except the prior emissions in the model were increased by $20 \%$. In this case the true emissions used to simulate the data were therefore $83 \%$ of the prior emissions. Four inversions were performed with the four simulated datasets, the results of which are shown in Fig. A1b. Again, the three experiments with random error and different biases return similar posterior fluxes. The inversions infer fluxes that agree with the truth to within $10 \%$, with the exception of Boreal Eurasia, Tropical and Temperate South America, and North and South Africa. In Boreal Eurasia this is likely due to a lack of observations due to the latitudinal filter used in the analysis. The other regions are all located in the tropics. In Tropical South America and North Africa, which are both mainly in the Northern Hemisphere, the performance may be a result of the relatively few measurements in the region, between 300 and 1100 per month for Tropical South America and between 350 and 1260 per month for North Africa (see Fig. 2), which are some of the smallest numbers for the nonboreal regions. In South Africa and Temperate South America, both located in the Southern Hemisphere, this is perhaps due to the seasonal cycle of the observations due to clouds and aerosols: both regions have a strong seasonal cycle with more observations in the austral winter (May-October) than in the austral summer (November-April). Other regions have seasonal cycles in the number of observations as well, though the amplitude in South Africa (amplitude 1600 observations, with minimum 580) and Temperate South America (amplitude 1270 observations, with minimum 700) is larger than any other region except Temperate Eurasia, which has a minimum of 1800 observations per month. The returned bias was within $1.5 \mathrm{ppb}$ of the true values in all of the experiments.

The third and final round of experiments was the same as the second, but in this case we perturbed the prior fluxes by a random number between -20 and $20 \%$ from the true fluxes. We again performed four inversions with the simulated datasets, the results of which are shown in Fig. A1c. The original perturbation to the prior fluxes is also given in this figure. The results in these experiments are similar to those of the second experiments, with the posterior fluxes in most regions agreeing with the true fluxes to within $10 \%$, with the exception of Boreal North America, Temperate South America, North Africa, and Boreal Eurasia. In the boreal regions, this is likely due to a lack of measurements. 
For the other regions, the reasons are likely the same as the second experiments. In the regions with differences in fluxes less than $10 \%$, the percentage difference between the prior and true fluxes is at least halved, even in areas with small differences to begin with.

We conclude that the GOSAT observing system is able to retrieve fluxes to within $10 \%$, and in some regions much better than this, of the "true" values in most regions. The observation pattern of the measurements and the conservative latitude-based filtering applied means that the system is not able to correct fluxes in the boreal regions. In tropical regions, the fluxes are over- or underestimated by up to $15 \%$ in our idealized experiments, possibly due to the small number and seasonal cycle of the observations leading to an incomplete sampling of the seasonal cycle. The inversions with the addition of different errors return similar fluxes, so we conclude that the assimilation system is not sensitive to random error on the order of magnitude of the measurement error of GOSAT or global or latitudinally varying biases. As more GOSAT data become available and the measurement distribution potentially changes these conclusions will need to be revisited.

\section{Appendix B}

\section{Bias correction}

The bias correction scheme is described in Sect. 4.1. Figure B1 shows the time series of the bias between the GOSAT GC proxy and the prior model in different latitudinal bands. No obvious trend is apparent in any of the latitude bands, indicating that the prior model generally reproduces the trend in the GOSAT $\mathrm{XCH}_{4}$ measurements. The bias varies with the latitude band, as expected from the comparisons in Fig. 2, with minimum values in the Southern Hemisphere extratropics and maximum values in the Northern Hemisphere tropics.

The initial value of the bias at $60^{\circ} \mathrm{S}, 30^{\circ} \mathrm{S}, 0^{\circ}, 30^{\circ} \mathrm{N}$, and $60^{\circ} \mathrm{N}$ was selected from the mean of the difference between the observations and prior model. Figure B2 shows the latitudinal distribution of the bias between the GOSAT GC proxy and the prior model, the first guess a priori bias, the retrieved bias, and a sensitivity study where the a priori bias was set to zero and the uncertainty in the nodes of the bias was increased to $15 \mathrm{ppb}$. This bias agrees very well with the bias retrieved in the standard inversion. The resultant fluxes from the sensitivity test are nearly identical to those retrieved in the standard inversion. We conclude that our inversion is not sensitive to the prior bias chosen.

We also performed sensitivity studies by changing the number and location of nodes. We find no significant difference in the posterior fluxes when the location of the nodes is changed. The fluxes are also robust to the number of nodes, provided there are at least two nodes; if a single node is
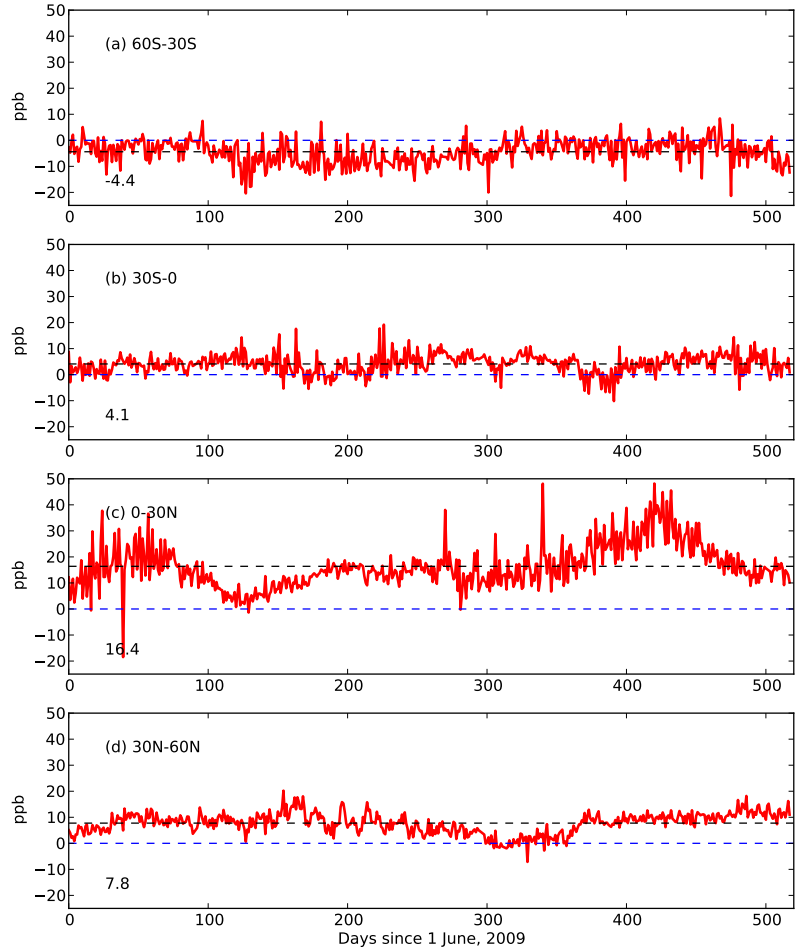

Fig. B1. Difference between the GOSAT GC proxy retrievals and the prior model for (a) $60^{\circ} \mathrm{S}-30^{\circ} \mathrm{S}$, (b) $30^{\circ} \mathrm{S}-0^{\circ}$, (c) $0^{\circ}-30^{\circ} \mathrm{N}$, and (d) $30^{\circ} \mathrm{N}-60^{\circ} \mathrm{N}$. The dashed blue line is at zero, while the dashed black line is the mean difference, the value of which is given in the lower left of each panel.

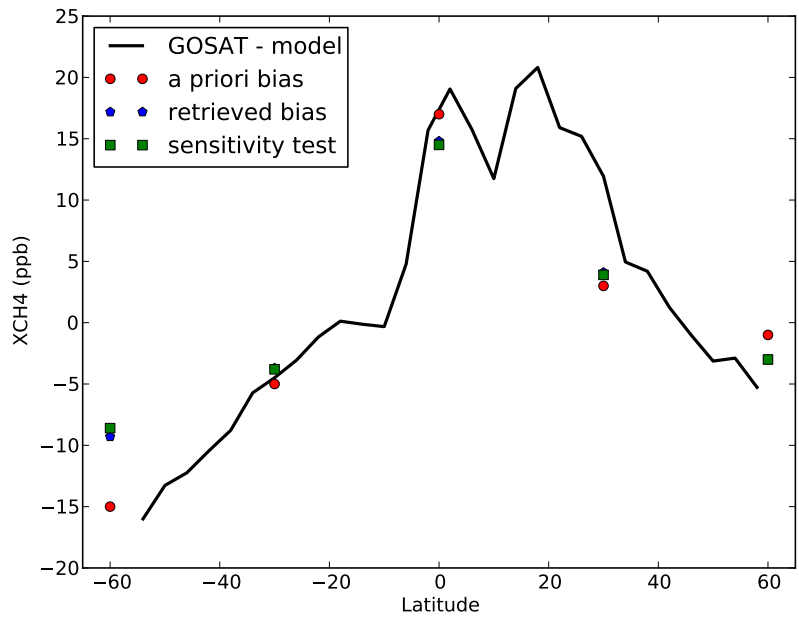

Fig. B2. Prior and posterior value of the bias at the five nodes defined in the inversion $\left(60^{\circ} \mathrm{S}, 30^{\circ} \mathrm{S}, 0^{\circ}, 30^{\circ} \mathrm{N}\right.$, and $\left.60^{\circ} \mathrm{N}\right)$. Also shown is the difference between the GOSAT GC proxy retrievals and the prior model averaged over the GOSAT data period (June 2009-December 2010). 

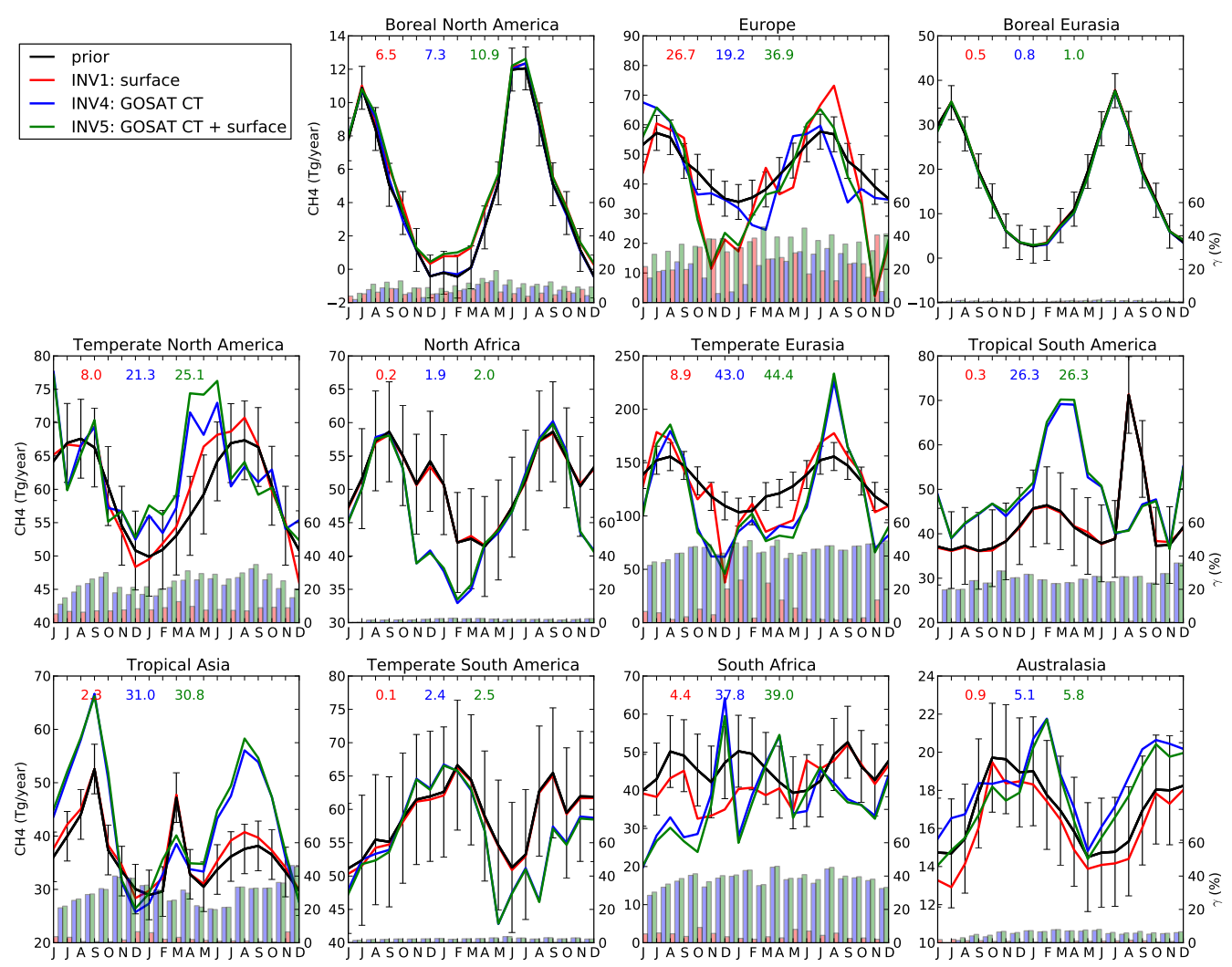

Fig. C1 As Fig. 4, but for the GOSAT CT proxy data.

used, which represents a global bias, the fluxes in the extratropical Northern Hemisphere are not greatly affected. The fluxes in the tropics and in the Southern Hemisphere, where the bias between the observations and the model is larger, become much smaller or larger than the prior, and can display some potentially unphysical variations. We choose an initial bias with five nodes to capture the variation in the bias with latitude, which could be partially due to biases in the GOSAT data resulting from thin cirrus clouds, sensitivity to the solar zenith angle of the satellite, uncertainties in water vapour spectroscopy, and the modelled $\mathrm{CO}_{2}$ used in the proxy method.

\section{Appendix C}

\section{Inversions using $\mathrm{CT}$ proxy data}

Figure $\mathrm{C} 1$ shows regional prior and posterior methane flux estimates over the study period inferred from surface data only, GOSAT CT proxy data only, and surface and CT proxy data. The posterior fluxes are similar to those found using the GOSAT GC proxy in Fig. 4. Differences between the results from the two proxies are a result of the differences between the $\mathrm{XCH}_{4}$ values in the proxies shown in Fig. 2.
Acknowledgements. A. Fraser, L. Feng and R. Parker are supported by the UK NERC National Centre for Earth Observation (NCEO) and $\mathrm{H}$. Boesch is supported by a RCUK fellowship. R. Parker and $\mathrm{H}$. Boesch also acknowledge support by the ESA Climate Change Initiative (CCI) project GHG-CCI via sub-contract with the University of Bremen. P. I. Palmer gratefully acknowledges support from the Leverhulme Trust. JAXA, NIES, and MOE provided the GOSAT data and provide support for work done at the University of Leicester as part of the Joint Research Agreement. The retrieval algorithm used for GOSAT was provided by the ACOS team at JPL. NOAA ESRL is supported by NOAA's Climate Program Office. CSIRO research at Cape Grim is supported by the Australian Bureau of Meteorology. AGAGE is supported by grants from NASA's Upper Atmosphere Research Program to R. G. Prinn and R. F. Weiss. We are grateful to Nicholas Deutscher, David Griffith, Frank Hase, Esko Kyrö, Isamu Morino, Justus Notholt, Vanessa Sherlock, Thorsten Warneke, and Paul Wennberg for the use of TCCON data, which were obtained from the TCCON Data Archive, operated by the California Institute of Technology from the website at http://tccon.ipac.caltech.edu/. We thank Frédéric Chevallier and Cindy Cressot for their helpful comments on a draft manuscript. We also thank the two anonymous reviewers for their comments which have helped to improve this manuscript.

Edited by: C. Gerbig 


\section{References}

Bergamaschi, P., Frankenberg, C., Meirink, J. F., Krol, M., Villani, M. G., Houweling, S., Dentener, F., Dlugokencky, E. J., Miller, J. B., Gatti, L. V., Engel, A., and Levin, I.: Inverse modeling of global and regional $\mathrm{CH}_{4}$ emissions using SCIAMACHY satellite retrievals, J. Geophys. Res., 114, D22301, doi:10.1029/2009JD012287, 2009.

Bloom, A. A., Palmer, P. I., Fraser, A., and Reay, D. S.: Seasonal variability of tropical wetland $\mathrm{CH}_{4}$ emissions: the role of the methanogen-available carbon pool, Biogeosciences, 9, 28212830, doi:10.5194/bg-9-2821-2012, 2012.

Boesch, H., Toon, G. C., Sen, B., Washenfelder, R. A., Wennberg, P. O., Buchwitz, M., de Beek, R., Burrows, J. P., Crisp, D., Christi, M., Connor, B. J., Natraj, V., and Yung, Y. L.: Spacebased near-infrared $\mathrm{CO}_{2}$ measurements: Testing the Orbiting Carbon Observatory retrieval algorithm and validation concept using SCIAMACHY observations over Park Falls, Wisconsin, J. Geophys. Res., 111, D23302, doi:10.1029/2006JD007080, 2006.

Boesch, H., Baker, D., Connor, B., Crisp, D., and Miller, C.: Global characterization of $\mathrm{CO}_{2}$ column retrievals from shortwave-infrared satellite observations of the Orbiting Carbon Observatory-2 mission, Remote Sens., 3, 270-304, doi:10.3390/rs3020270, 2011.

Bousquet, P., Cialis, P., Miller, J. B., Dlugokencky, E. J., Hauglustaine, D. A., Prigent, C., van der Werf, G. R., Peylin, P., Brunke, E.-G., Carouge, C., Langenfelds, R. L., Lathière, J., Papa, F., Ramonet, M., Schmidt, M., Steele, L. P., Tyler, S. C., and White, J.: Contribution of anthropogenic and natural sources to atmospheric methane variability, Nature, 443, 439443, doi:10.1038/nature05132, 2006.

Butz, A., Hasekamp, O. P., Frankenberg, C., Vidot, J., and Aben, I.: $\mathrm{CH}_{4}$ retrievals from space-based solar backscatter measurements: Performance evaluation against simulated aerosol and cirrus loaded scenes, J. Geophys. Res., 115, D24302, doi:10.1029/2010JD014514, 2010.

Chen, Y.-H. and Prinn, R. G.: Estimation of atmospheric methane emissions between 1996 and 2001 using a three-dimensional global chemical transport model, J. Geophys. Res., 111, D10307, doi:10.1029/2005JD006058, 2006.

Cogan, A. J., Boesch, H., Parker, R. J., Feng, L., Palmer, P. I., Blavier, J.-F. L., Deutscher, N. M., Macatangay, R., Notholt, J., Roehl, C., Warneke, T., and Wunch, D.: Atmospheric carbon dioxide retrieved from the Greenhouse gases Observing SATellite (GOSAT): Comparison with ground-based TCCON observations and GEOS-Chem model calculations, J. Geophys. Res., 117, D21301, doi:10.1029/2012JD018087, 2012.

Crisp, D., Fisher, B. M., O’Dell, C., Frankenberg, C., Basilio, R., Bösch, H., Brown, L. R., Castano, R., Connor, B., Deutscher, N. M., Eldering, A., Griffith, D., Gunson, M., Kuze, A., Mandrake, L., McDuffie, J., Messerschmidt, J., Miller, C. E., Morino, I., Natraj, V., Notholt, J., O’Brien, D. M., Oyafuso, F., Polonsky, I., Robinson, J., Salawitch, R., Sherlock, V., Smyth, M., Suto, H., Taylor, T. E., Thompson, D. R., Wennberg, P. O., Wunch, D., and Yung, Y. L.: The ACOS $\mathrm{CO}_{2}$ retrieval algorithm - Part II: Global $\mathrm{XCO}_{2}$ data characterization, Atmos. Meas. Tech., 5, 687-707, doi:10.5194/amt-5-687-2012, 2012.

Cunnold, D. M., Steele, L. P., Fraser, P. J., Simmonds, P. G., Prinn, R. G., Weiss, R. F., Porter, L. W., O’Doherty, S., Langenfelds, R. L., Krummel, P. B., Wang, H. J., Emmons, L.,
Tie, X. X., and Dlugokencky, E. J.: In situ measurements of atmospheric methane at GAGE/AGAGE sites during 1985-2000 and resulting source inferences, J. Geophys. Res., 107, 4225, doi:10.1029/2001JD001226, 2002.

Dlugokencky, E. J., Myers, R. C., Lang, P. M., Masarie, K. A., Crotwell, A. M., Thoning, K. W., Hall, B. D., Elkins, J. W., and Steele, L. P.: Conversion of NOAA atmospheric dry air $\mathrm{CH}_{4}$ mole fractions to a gravimetrically prepared standard scale, J. Geophys. Res., 110, D18306, doi:10.1029/2005JD006035, 2005.

Dlugokencky, E. J., Lang, P. M., and Masarie, K. A.: Atmospheric methane dry air mole fractions from the NOAA ESRL carbon cycle cooperative global air sampling network, 1983-2010, Version: 2011-10-14, 2011.

Feng, L., Palmer, P. I., Bösch, H., and Dance, S.: Estimating surface $\mathrm{CO}_{2}$ fluxes from space-borne $\mathrm{CO}_{2}$ dry air mole fraction observations using an ensemble Kalman Filter, Atmos. Chem. Phys., 9, 2619-2633, doi:10.5194/acp-9-2619-2009, 2009.

Feng, L., Palmer, P. I., Yang, Y., Yantosca, R. M., Kawa, S. R., Paris, J.-D., Matsueda, H., and Machida, T.: Evaluating a 3-D transport model of atmospheric $\mathrm{CO}_{2}$ using ground-based, aircraft, and space-borne data, Atmos. Chem. Phys., 11, 27892803, doi:10.5194/acp-11-2789-2011, 2011.

Fiore, A., Jacob, D. J., Liu, H., Yantosca, R. M., Fairlie, T. D., and Li, Q.: Variability in surface ozone background over the United States: Implications for air quality policy, J. Geophys. Res., 108, 4787, doi:10.1029/2003JD003855, 2003.

Francey, R. J., Steele, L. P., Langenfelds, R. L., Lucarelli, M. P., Allison, C. E., Beardsmore, D. J., Coram, S. A., Derek, N., de Silva, F. R., Etheridge, D. M., Fraser, P. J., Henry, R. J., Turner, B., Welch, E. D., Spencer, D. A., and Cooper, L. N.: Baseline Atmospheric Program (Australia), chap. Global Atmospheric Sampling Laboratory (GASLAB): supporting and extending the Cape Grim trace gas programs, 8-29, Bureau of Meteorology and CSIRO Division of Atmospheric Research, Melbourne, Australia, 1996.

Frankenberg, C., Aben, I., Bergamaschi, P., Dlugokencky, E. J., van Hees, R., Houweling, S., van der Meer, P., Snel, R., and Tol, P.: Global column-averaged methane mixing ratios from 2003 to 2009 as derived from SCIAMACHY: Trends and variability, J. Geophys. Res., 116, D04302, doi:10.1029/2010JD014849, 2011.

Fraser, A., Chan Miller, C., Palmer, P. I., Deutscher, N. M., Jones, N. B., and Griffith, D. W. T.: The Australian methane budget: Interpreting surface and train-borne measurements using a chemistry transport model, J. Geophys. Res., 116, D20306, doi:10.1029/2011JD015964, 2011.

Fung, I., John, J., Lerner, J., Matthews, E., Prather, M., Steele, L. P., and Fraser, P. J.: Three-Dimensional model synthesis of the global methane cycle, J. Geophys. Res., 96, 13033-13065, doi:10.1029/91JD01247, 1991.

Gurney, K. R., Law, R. M., Denning, A. S., Rayner, P. J., Baker, D., Bousquet, P., Bruhwiler, L., Chen, Y.-H., Ciais, P., Fan, S., Fung, I. Y., Gloor, M., Heimann, M., Higuchi, K., John, J., Maki, T., Maksyutov, S., Masarie, K., Peylin, P., Prather, M., Pak, B. C., Randerson, J., Sarmiento, J., Taguchi, S., Takahashi, T., and Yuen, C.-W.: Towards robust regional estimates of $\mathrm{CO}_{2}$ sources and sinks using atmospheric transport models, Nature, 415, 626630, doi:10.1038/415626a, 2002.

Heymann, J., Schneising, O., Reuter, M., Buchwitz, M., Rozanov, V. V., Velazco, V. A., Bovensmann, H., and Burrows, J. P.: SCIA- 
MACHY WFM-DOAS $\mathrm{XCO}_{2}$ : comparison with CarbonTracker $\mathrm{XCO}_{2}$ focusing on aerosols and thin clouds, Atmos. Meas. Tech., 5, 1935-1952, doi:10.5194/amt-5-1935-2012, 2012.

Houweling, S., Kaminski, T., Dentener, F., Lelieveld, J., and Heimann, M.: Inverse modeling of methane sources and sinks using the adjoint of a global transport model, J. Geophys. Res., 104, 26137-26160, doi:10.1029/1999JD900428, 1999.

Kirschke, S., Bousquet, P., Ciais, P., Saunois, M., Bergamaschi, P., Bruhwiler, L., Canadell, J. G., Chevallier, F., Dlugokencky, E. J., Feng, L., Fraser, A., Heimann, M., Hodson, E., Houweling, S., Josse, B., Lamarque, J.-F., Quéré, C. L., Nagashima, T., Naik, V., Palmer, P., Pison, I., Poulter, B., Ringeval, B., Shindell, D. T., Spahni, R., Strode, S. A., Szopa, S., van der Werf, G. R., Voulgarakis, A., and Zeng, G.: Three decades of methane sources and sinks: budgets and variations, Nature Geosci., in press, 2013.

Kuze, A., Suto, H., Nakajima, M., and Hamazaki, T.: Thermal and near infrared sensor for carbon observation Fourier-transform spectrometer on the Greenhouse Gases Observing Satellite for greenhouse gases monitoring, Appl. Optics, 48, 6716-6733, doi:10.1364/AO.48.006716, 2009.

Niwa, Y., Machida, T., Sawa, Y., Matsueda, H., Schuck, T. J., Brenninkmeijer, C. A. M., Imasu, R., and Satoh, M.: Imposing strong constraints on tropical terrestrial $\mathrm{CO}_{2}$ fluxes using passenger aircraft based measurements, J. Geophys. Res., 117, D11303, doi:10.1029/2012JD017474, 2012.

Olivier, J. G. J., van Aardenne, J. A., Dentener, F., Ganzeveld, L., and Peters, J. A. H. W.: Recent trends in global greenhouse gas emissions: regional trends and spatial distribution of key sources, in: Non- $\mathrm{CO}_{2}$ Greenhouse Gases (NCGG-4), edited by: van Amstel, A., 325-330, Millpress, Rotterdam, 2005.

Palmer, P. I., Feng, L., and Bösch, H.: Spatial resolution of tropical terrestrial $\mathrm{CO}_{2}$ fluxes inferred using space-borne column $\mathrm{CO}_{2}$ sampled in different earth orbits: the role of spatial error correlations, Atmos. Meas. Tech., 4, 1995-2006, doi:10.5194/amt-41995-2011, 2011.

Parker, R., Boesch, H., Cogan, A., Fraser, A., Feng, L., Palmer, P. I., Messerschmidt, J., Deutscher, N., Griffith, D. W., Notholt, J., Wennberg, P. O., and Wunch, D.: Methane observations from the Greenhouse Gases Observing SATellite: Comparison to groundbased TCCON data and model calculations, Geophys. Res. Lett., 38, L15807, doi:10.1029/2011GL047871, 2011.

Patra, P. K., Houweling, S., Krol, M., Bousquet, P., Belikov, D., Bergmann, D., Bian, H., Cameron-Smith, P., Chipperfield, M. P., Corbin, K., Fortems-Cheiney, A., Fraser, A., Gloor, E., Hess, P., Ito, A., Kawa, S. R., Law, R. M., Loh, Z., Maksyutov, S., Meng, L., Palmer, P. I., Prinn, R. G., Rigby, M., Saito, R., and Wilson, C.: TransCom model simulations of $\mathrm{CH}_{4}$ and related species: linking transport, surface flux and chemical loss with $\mathrm{CH}_{4}$ variability in the troposphere and lower stratosphere, Atmos. Chem. Phys., 11, 12813-12837, doi:10.5194/acp-11-12813-2011, 2011.

Peters, W., Jacobson, A. R., Sweeney, C., Andrews, A. E., Conway, T. J., Masarie, K., Miller, J. B., Bruhwiler, L. M. P., Pétron, G., Hirsch, A. I., Worthy, D. E. J., van der Werf, G. R., Randerson, J. T., Wennberg, P. O., Krol, M. C., and Tans, P. P.: An atmospheric perspective on North American carbon dioxide exchange: CarbonTracker, P. Natl. Acad. Sci. USA, 104, 1892518930, doi:10.1073/pnas.0708986104, 2007.

Prinn, R. G., Weiss, R. F., Fraser, P. J., Simmonds, P. G., Cunnold, D. M., Alyea, F. N., O’Doherty, S., Salameh, P., Miller,
B. R., Huang, J., Wang, R. H. J., Hartley, D. E., Harth, C., Steele, L. P., Sturrock, G., Midgley, P. M., and McCulloch, A.: A history of chemically and radiatively important gases in air deduced from ALE/GAGE/AGAGE, J. Geophys. Res., 105, 1775117792, doi:10.1029/2000JD900141, 2000.

Razavi, A., Clerbaux, C., Wespes, C., Clarisse, L., Hurtmans, D., Payan, S., Camy-Peyret, C., and Coheur, P. F.: Characterization of methane retrievals from the IASI space-borne sounder, Atmospheric Chemistry and Physics, 9, 7889-7899, doi:10.5194/acp9-7889-2009, 2009.

Rigby, M., Prinn, R. G., Fraser, P. J., Simmonds, P. G., Langenfelds, R. L., Huang, J., Cunnold, D. M., Steele, L. P., Krummel, P. B., Weiss, R. F., O'Doherty, S., Salameh, P. K., Wang, H. J., Harth, C. M., Mühle, J., and Porter, L. W.: Renewed growth of atmospheric methane, Geophys. Res. Lett., 35, L22805, doi:10.1029/2008GL036037, 2008.

Schepers, D., Guerlet, S., Butz, A., Landgraf, J., Frankenberg, C., Hasekamp, O., Blavier, J.-F., Deutscher, N. M., Griffith, D. W. T., Hase, F., Kyro, E., Morino, I., Sherlock, V., Sussmann, R., and Aben, I.: Methane retrievals from Greenhouse Gases Observing Satellite (GOSAT) shortwave infrared measurements: Performance comparison of proxy and physics retrieval algorithms, J. Geophys. Res., 117, D10307, doi:10.1029/2012JD017549, 2012.

Schneising, O., Buchwitz, M., Reuter, M., Heymann, J., Bovensmann, H., and Burrows, J. P.: Long-term analysis of carbon dioxide and methane column-averaged mole fractions retrieved from SCIAMACHY, Atmos. Chem. Phys., 11, 28632880, doi:10.5194/acp-11-2863-2011, 2011.

Spahni, R., Wania, R., Neef, L., van Weele, M., Pison, I., Bousquet, P., Frankenberg, C., Foster, P. N., Joos, F., Prentice, I. C., and van Velthoven, P.: Constraining global methane emissions and uptake by ecosystems, Biogeosciences, 8, 1643-1665, doi:10.5194/bg8-1643-2011, 2011.

van der Werf, G. R., Randerson, J. T., Giglio, L., Collatz, G. J., Mu, M., Kasibhatla, P. S., Morton, D. C., DeFries, R. S., Jin, Y., and van Leeuwen, T. T.: Global fire emissions and the contribution of deforestation, savanna, forest, agricultural, and peat fires (19972009), Atmos. Chem. Phys., 10, 11707-11735, doi:10.5194/acp10-11707-2010, 2010.

Wang, J. S., Logan, J. A., McElroy, M. B., Duncan, B. N., Megretskaia, I. A., and Yantosca, R. M.: A 3-D model analysis of the slowdown and interannual variability in the methane growth rate from 1988 to 1997, Global Biogeochem. Cy., 18, GB3011, doi:10.1029/2003GB002180, 2004.

Wunch, D., Toon, G. C., Wennberg, P. O., Wofsy, S. C., Stephens, B. B., Fischer, M. L., Uchino, O., Abshire, J. B., Bernath, P., Biraud, S. C., Blavier, J.-F. L., Boone, C., Bowman, K. P., Browell, E. V., Campos, T., Connor, B. J., Daube, B. C., Deutscher, N. M., Diao, M., Elkins, J. W., Gerbig, C., Gottlieb, E., Griffith, D. W. T., Hurst, D. F., Jiménez, R., Keppel-Aleks, G., Kort, E. A., Macatangay, R., Machida, T., Matsueda, H., Moore, F., Morino, I., Park, S., Robinson, J., Roehl, C. M., Sawa, Y., Sherlock, V., Sweeney, C., Tanaka, T., and Zondlo, M. A.: Calibration of the Total Carbon Column Observing Network using aircraft profile data, Atmos. Meas. Tech., 3, 1351-1362, doi:10.5194/amt3-1351-2010, 2010.

Wunch, D., Toon, G. C., Blavier, J.-F. L., Washenfelder, R., Notholt, J., Connor, B. J., Griffith, D. W. T., Sherlock, V., and Wennberg, P. O.: The Total Carbon Column Observing 
Network (TCCON), Philos. T. R. Soc. A, 369, 2087-2112, doi:10.1098/rsta.2010.0240, 2011a.

Wunch, D., Wennberg, P. O., Toon, G. C., Connor, B. J., Fisher, B., Osterman, G. B., Frankenberg, C., Mandrake, L., O’Dell, C., Ahonen, P., Biraud, S. C., Castano, R., Cressie, N., Crisp, D., Deutscher, N. M., Eldering, A., Fisher, M. L., Griffith, D. W. T., Gunson, M., Heikkinen, P., Keppel-Aleks, G., Kyrö, E., Lindenmaier, R., Macatangay, R., Mendonca, J., Messerschmidt, J., Miller, C. E., Morino, I., Notholt, J., Oyafuso, F. A., Rettinger, M., Robinson, J., Roehl, C. M., Salawitch, R. J., Sherlock, V., Strong, K., Sussmann, R., Tanaka, T., Thompson, D. R., Uchino, O., Warneke, T., and Wofsy, S. C.: A method for evaluating bias in global measurements of $\mathrm{CO}_{2}$ total columns from space, Atmos. Chem. Phys., 11, 12317-12337, doi:10.5194/acp11-12317-2011, $2011 \mathrm{~b}$. 